\title{
Piezo2 Mediates Low-Threshold Mechanically Evoked Pain in the Cornea
}

\author{
๑Dorge Fernández-Trillo, ${ }^{\circledR D}$ Danny Florez-Paz, ${ }^{\circledR}$ Almudena Íñigo-Portugués, Omar González-González, \\ - Ana Gómez del Campo, ${ }^{-}$Alejandro González, ${ }^{\circledR}$ Félix Viana, ${ }^{-C a r l o s}$ Belmonte, and ${ }^{\circledR}$ Ana Gomis \\ Instituto de Neurociencias, Universidad Miguel Hernández-Consejo Superior de Investigaciones Científicas, 03550 San Juan de Alicante, Alicante, Spain
}

Mammalian Piezo2 channels are essential for transduction of innocuous mechanical forces by proprioceptors and cutaneous touch receptors. In contrast, mechanical responses of somatosensory nociceptor neurons evoking pain, remain intact or are only partially reduced in Piezo2-deficient mice. In the eye cornea, comparatively low mechanical forces are detected by polymodal and pure mechanosensory trigeminal ganglion neurons. Their activation always evokes ocular discomfort or pain and protective reflexes, thus being a unique model to study mechanotransduction mechanisms in this particular class of nociceptive neurons. Cultured male and female mouse mechano- and polymodal nociceptor corneal neurons display rapidly, intermediately and slowly adapting mechanically activated currents. Immunostaining of the somas and peripheral axons of corneal neurons responding only to mechanical force (pure mechano-nociceptor) or also exhibiting TRPV1 (transient receptor potential cation channel subfamily V member 1) immunoreactivity (polymodal nociceptor) revealed that they express Piezo2. In sensory-specific Piezo2-deficient mice, the distribution of corneal neurons displaying the three types of mechanically evoked currents is similar to the wild type; however, the proportions of rapidly adapting neurons, and of intermediately and slowly adapting neurons were significantly reduced. Recordings of mechano- and polymodal-nociceptor nerve terminals in the corneal surface of Piezo2 conditional knock-out mice revealed a reduced number of mechano-sensitive terminals and lower frequency of nerve terminal impulse discharges under mechanical stimulation. Eye blinks evoked by von Frey filaments applied on the cornea were lower in Piezo2-deficient mice compared with wild type. Together, our results provide direct evidence that Piezo2 channels support mechanically activated currents of different kinetics in corneal trigeminal neurons and contributes to transduction of mechanical forces by corneal nociceptors.

Key words: cornea; mechanosensation; nociceptor; pain; Piezo2; trigeminal

\section{Significance Statement}

The cornea is a richly innervated and highly sensitive tissue. Low-threshold mechanical forces activate corneal receptors evoking discomfort or pain. To examine the contribution of Piezo2, a low-threshold mechanically activated channel, to acute ocular pain, we characterized the mechanosensitivity of corneal sensory neurons. By using Piezo2 conditional knock-out mice, we show that Piezo2 channels, present in the cell body and terminals of corneal neurons, are directly involved in acute corneal mechano-nociception. Inhibition of Piezo2 for systemic pain treatment is hindered because of its essential role for mechanotransduction processes in multiple body organs. Still, topical modulation of Piezo2 in the cornea may be useful to selectively relief unpleasant sensations and pain associated with mechanical irritation accompanying many ocular surface disorders.

Received Jan. 22, 2020; revised 0ct. 5, 2020; accepted 0ct. 7, 2020.

Author contributions: F.V., C.B., and A. Gomis designed research; J.F.-T., D.F.-P., A.I..-P., 0.G.-G., A.G.d.C.,

A. González, and A. Gomis performed research; J.F.-T., D.F.-P., A.I..-P., 0.G.-G., A.G.d.C., A. González, and

A. Gomis analyzed data; J.F-T, F.V. and C.B. edited the paper; A. Gomis wrote the paper.

This research was supported by the following Spanish Government projects: SAF2016-77233R and PID2019-108194RB-100 (A. Gomis and F.V.) and the "Severo Ochoa" Program for Centers of Excellence in R\&D (SEV-2017-0723). A.I.-P. and 0.G.-G. were supported by the project SAF2017-83674-C2-1-R and C2-2R. We thank Ardem Patapoutian and Paul Heppenstall for providing the Piezo2 ${ }^{f / f l}$ and Advillin-Cre mice respectively; and Salvador Sala for helping with current kinetic analysis and to Manuela Schmidt for advice with immunohistochemistry in Piezo2GFP mice. We also thank Mireille Tora and Eva Quintero for excellent technical assistance, and Carlos Ramos and Sergio Javaloy for illustrations. In addition, we thank all members of the Sensory Transduction and Nociception Group for useful comments and suggestions.

The authors declare no competing financial interests.

D. Florez-Paz's present address: Department of Pathology and Cell Biology, Columbia University, New York, NY 10032. Correspondence should be addressed to Ana Gomis at agomis@umh.es.

https://doi.org/10.1523/JNEUROSCI.0247-20.2020

Copyright $\odot 2020$ the authors

\section{Introduction}

Precise and rapid detection of mechanical forces is crucial for living organisms. The mammalian skin, mucosae, muscles, and joints are equipped with peripheral endings of multiple classes of somatosensory ganglion neurons activated by mechanical stimuli. Cultured cell bodies of these mechanosensory neurons display distinct types of mechanically activated (MA) inward currents, classified according to their inactivation kinetics as rapidly adapting (RA), intermediately adapting (IA), and slowly adapting (SA). RA currents are more common in low-threshold mechanoreceptor neurons (LTMR), while IA and SA are mainly found in high-threshold mechanoreceptor neurons, although this 
segregation is by no means exclusive (Drew et al., 2002; Hu and Lewin, 2006; Hao and Delmas, 2010).

Piezo2 was identified as an ion channel expressed in dorsal root ganglion (DRG; Coste et al., 2010; Woo et al., 2014) and trigeminal ganglion (TG) neurons (Bron et al., 2014; Schneider et al., 2014, 2017; Nguyen et al., 2017) and selectively activated by innocuous mechanical forces (Ranade et al., 2014; Woo et al., 2014; Florez-Paz et al., 2016). However, Piezo2 was also identified in neurons expressing nociceptive markers, suggesting a potential role in noxious mechanosensation (Coste et al., 2010; Nguyen et al., 2017; Szczot et al., 2017; Murthy et al., 2018b; Zhang et al., 2019).

Genetic ablation of Piezo2 in mice produced deficits in somatic low-threshold mechanosensitivity (Woo et al., 2015; Florez-Paz et al., 2016), while responses to noxious mechanical forces in cutaneous nociceptor neurons were diminished partially (Murthy et al., 2018b) or remained largely unaffected (Ranade et al., 2014; Szczot et al., 2018), even after nerve injury or chronic inflammation (Szczot et al., 2018). Moreover, humans carrying Piezo2-inactivating variants showed selective loss of discriminative touch and decreased proprioception, while responses to cutaneous pinprick and pressure pain were unaltered (Chesler et al., 2016; Szczot et al., 2018). Nonetheless, other experimental evidence points toward an involvement of Piezo2 in NGFinduced mechanosensitivity of "silent" nociceptors (Prato et al., 2017) and in mechanical allodynia (Murthy et al., 2018b), thus challenging the existence of an univocal association between a specific mechanotransducing molecule such as Piezo2, and the qualitatively distinct innocuous and painful conscious percepts evoked respectively by low- and high-intensity mechanical forces.

The cornea is the most densely innervated surface epithelium in the human body, a vital characteristic in protecting this exposed tissue from injury. Unmyelinated free nerve endings of corneal sensory axons originated in TG cell bodies ramify close to the surface of the corneal epithelium (Weddell and Zander, 1950; Marfurt et al., 2010). Functionally, three distinct populations of corneal nerve terminals have been identified (Belmonte et al., 1997; González-González et al., 2017); pure mechano-nociceptors, which respond exclusively to low-intensity mechanical forces, and polymodal nociceptors, which are activated by analogous mechanical stimuli, heat and chemical irritants, and cold thermoreceptors, responding to temperature decreases (Belmonte and Giraldez, 1981; Gallar et al., 1993; Belmonte et al., 2017). In humans, all conscious sensations resulting from the stimulation of the cornea contain a defined unpleasant or painful perceptual component (Beuerman and Tanelian, 1979; Belmonte et al., 1999), except for the ambiguous feeling of cooling evoked by small corneal surface temperature reductions (Acosta et al., 2001). These characteristics are coherent with the protective role of corneal sensory innervation against tissue damage.

The involvement of Piezo2 channels in nociception is still unclear, thus requiring a deeper study in different nociceptive neuronal classes. Interestingly, a fraction of corneal TG neurons expresses Piezo2 (Bron et al., 2014). Here, we sought to explore the role of Piezo2 in acute nociception, using corneal neurons, where low-intensity mechanical forces evoke sensations of discomfort or pain. Our results show that Piezo2 contributes to mechanosensitivity of corneal nociceptive neurons. This result has therapeutic significance for the treatment of ocular pain and is conceptually relevant in defining the complex correspondence between the expression of specific transduction molecules by the different cohorts of peripheral sensory neurons and the distinct perceptual characteristics of the sensations evoked by their excitation.

\section{Materials and Methods}

All experimental procedures were performed in accordance with the Spanish Royal Decree 1201/2005 and the European Community Council Directive 2010/63/EU. Adult mice of either sex were used. Mice were housed in a temperature-controlled room $\left(21^{\circ} \mathrm{C}\right)$ on a $12 \mathrm{~h} \mathrm{light/dark}$ cycle, with access to food and water ad libitum.

\section{Mouse lines}

Adult C57BL/6J wild-type (WT) mice (https://www.jax.org/strain/ 000664) and five different transgenic mouse lines were used in this study. We generated conditional Piezo2 knock-out mice $\left(\right.$ Piezo2 $\left.{ }^{c K O}\right)$ on a C57BL/6J background by crossing an Advillin-Cre line (Zurborg et al., 2011) with floxed Piezo2 mice (https://www.jax.org/strain/027720; Woo et al., 2014). The Advillin-Cre is a bacterial artificial chromosome (BAC) transgenic Cre-driver mouse line that expresses Cre-recombinase under the regulatory elements of the Advillin gene (Zurborg et al., 2011). Expression analysis showed that Advillin is mainly restricted to peripheral sensory ganglia in adult mice (Zurborg et al., 2011). Floxed Piezo2 mice $($ Piezo fl/fl) present two loxP sites flanking exons 43 through 45 (Woo et al., 2014). In Piezo2 ${ }^{c K O}$ mouse, Piezo2 is ablated in neurons from peripheral sensory ganglia. Littermates of this line were also used as wild-type controls. Different genotypes were used for this purpose: mice that did not carry the Advillin-Cre allele and were homozygous, heterozygous, or null for the floxed Piezo2 allele or mice with the positive Cre allele and null alleles for Piezo $2^{f l f l}$. Piezo2GFP-Cre mice (Woo et al., 2014) is a knock-in line, expressing GFP fused to Piezo2 (https://www.jax.org/strain/027719). Trpv1-GFP mice, a strain from the GENSAT collection, were obtained from the MMRRC Repository (033029-UCD) at University of California, Davis (http://www.informatics. jax.org/allele/MGI:4847511; MMRRC Services, The Rockefeller University, New York, NY) and backcrossed to a C57BL/6J background. An EGFP (enhanced green fluorescent protein) reporter gene was inserted into a BAC clone at the initiating ATG codon of the first coding exon of the Trpv1 gene so that EGFP expression is driven by the regulatory sequences of the Trpv1 gene. In $\operatorname{Trpm} 8^{\mathrm{BAC}}$-EYFP mice, generated in our laboratory, yellow fluorescent protein (YFP) is expressed under the Trpm 8 promoter (MorenillaPalao et al., 2014). The genotype of the different transgenic mice used was established by PCR. The primers and genotyping protocols are available on request.

\section{Retrograde labeling of corneal TG neurons}

Trigeminal sensory neurons innervating the mouse cornea were identified with the retrograde tracers FM 1-43FX (Thermo Fisher Scientific) and Fast Blue (Polyscience Europe). In most animals, the labeling of corneal neurons was done using FM 1-43FX $(100 \mu \mathrm{M})$. Adult mice were anesthetized with an intraperitoneal injection of a solution containing ketamine $(90 \mathrm{mg} / \mathrm{kg})$ and xylazine $(15 \mathrm{mg} / \mathrm{kg}$; injection, $5 \mu \mathrm{l} / \mathrm{g})$. Also, a dose of buprenorphine was injected subcutaneously $(0.1 \mathrm{mg} / \mathrm{kg})$. Additionally, we applied local anesthesia, 1 drop of a mixture of tetracaine $(4 \mathrm{mg} / \mathrm{ml})$ and oxibuprocain $(4 \mathrm{mg} / \mathrm{ml})$, to the right eye (only one eye was labeled in each mouse). To remove the corneal epithelium, an absorbable hemostatic gelatin sponge disk (diameter, $3 \mathrm{~mm}$ ) soaked with ethanol $70 \%$ was placed on the corneal surface for $30 \mathrm{~s}$. Thereafter, the corneal epithelium was slightly scraped using a surgical blade exposing the nerve terminals, and a Gelfoam sponge soaked with $100 \mu \mathrm{M}$ FM 1-43 FX or with Fast Blue ( $5 \%$ in distilled water) was placed on the de-epithelized corneal surface for $40 \mathrm{~min}$. During incubation with the retrograde label, the animals were maintained in the dark in a veterinary recovery chamber at $35^{\circ} \mathrm{C}$ (MediHeat V1200, Peco Services); after $20 \mathrm{~min}$ of incubation, the Gelfoam sponge was remoistened $(2-3 \mu \mathrm{l})$ with the labeling solution and left for 20 additional minutes. Then, the sponge was removed by moistening with saline and the eye was washed out with saline. A drop of tobramycin $(3 \mathrm{mg} / \mathrm{ml})$ was applied to the eye to prevent corneal infections; the eye was rinsed with saline after each described step. A drop of artificial 
tear was applied to the untreated eye during the labeling procedure. Mice were kept 3-4 d after labeling to allow the transport of the tracer from the corneal terminals to the soma in the TG and then were killed for cell culture. Fluorescence of intact TG was visualized with a MZ16FA Stereomicroscope (Leica Microsystems) and a QiClick-FM-12 camera (Q-Imaging).

\section{Neuronal cell culture}

Mice were killed by cervical dislocation followed by decapitation. Trigeminal corneal neurons were cultured as described previously (Viana et al., 2001). Briefly, the ocular branch of the TG of the labeled eye was dissected out and incubated in a mix of collagenase type XI (900 u/ml; Sigma-Aldrich) and dispase $(3 \mathrm{mg} / \mathrm{ml}$; Thermo Fisher Scientific) in INCmix medium (in mM: $155 \mathrm{NaCl}, 1.5 \mathrm{~K}_{2} \mathrm{PO}_{4}, 10$ HEPES, and 5 glucose buffered to $\mathrm{pH} 7.4$ ) containing $1 \%$ penicillin and streptomycin for $40 \mathrm{~min}$ at $37^{\circ} \mathrm{C}$ in $5 \% \mathrm{CO}_{2}$. Ophthalmic branches of labeled TG ganglia from two mice were then dissociated mechanically via trituration with flame-polished Pasteur pipettes to break down the tissue. Enzymes were stopped by adding HBSS medium containing 1\% MEM Vitamin Solution, 10\% FBS, and $1 \%$ penicillin and streptomycin, followed by centrifugation at $850 \mathrm{rpm}$ for $5 \mathrm{~min}$. The pellets were resuspended in Eagle's minimal essential medium, 1\% MEM Vitamin Solution, 10\% FBS, 1\% penicillin and streptomycin (all from Thermo Fisher Scientific). Cell suspensions were plated on poly-L-lysine-coated glass coverslips and maintained at $37^{\circ} \mathrm{C}$ in $5 \% \mathrm{CO}_{2}$ and used $24 \mathrm{~h}$ after plating. At the start of the experiment, images of neurons were obtained using the recording microscope with transmitted light and under $488 \mathrm{~nm}$ excitation wavelength (FM 1-43FX) or $365 \mathrm{~nm}$ (Fast Blue) to identify retrogradely labeled fluorescent cells.

Whole-cell recordings and mechanical stimulation

Patch-clamp recordings were performed in the current-clamp and voltage-clamp whole-cell configuration using a Multiclamp 700B amplifier, connected to a Digidata 1322A Data Acquisition System and controlled by pCLAMP 10 software (Molecular Devices). Experiments were performed at a temperature of $32-34^{\circ} \mathrm{C}$. Temperature was controlled by a homemade water-cooled Peltier system controlled by a feedback device. Cells were held at $-60 \mathrm{mV}$, and data were sampled at a frequency of $20 \mathrm{kHz}$ and low-passed filtered at $10 \mathrm{kHz}$. Recordings were not adjusted for the pipette liquid junction potential of $+12 \mathrm{mV}$, which was calculated as previously described (Neher, 1992). This was very similar to the estimated value using the junction potential calculator included in the pClamp software (about $+13 \mathrm{mV}$ ). The control external solution contained the following (in $\mathrm{mM}$ ): $140 \mathrm{NaCl}, 3 \mathrm{KCl}, 1 \mathrm{CaCl}_{2}, 2 \mathrm{MgCl}_{2}, 10$ glucose, and 10 HEPES, at pH $7.2(300 \mathrm{mOsm} / \mathrm{kg})$. Borosilicate glass capillary patch-pipettes of 4-7 M $\Omega$ resistance were filled with intracellular solution containing (in $\mathrm{mm}$ ): $115 \mathrm{~K}$-gluconate, $25 \mathrm{KCl}, 9 \mathrm{NaCl}, 10$ HEPES, 0.2 EGTA, $1 \mathrm{MgCl}_{2}, 3 \mathrm{~K}_{2}$-ATP, and $1 \mathrm{Na}$-GTP adjusted to $\mathrm{pH}$ 7.2 with $\mathrm{KOH}(280-290 \mathrm{mOsm} / \mathrm{kg})$. Injection of current pulses varying from $-20 \mathrm{pA}$ to $900 \mathrm{nA}$ over $300 \mathrm{~ms}$ was used to evoke action potentials.

The recording chamber was placed on the stage of a Leica DMI 3000B inverted microscope. Labeled TG neurons were identified under fluorescence excitation with a Lambda 10-2 Filter Wheel (Sutter Instruments), and the emitted fluorescence, of FM 1-43 or Fast Blue, was long-pass filtered at 510 and $420 \mathrm{~nm}$, respectively, to the dye used. The images were acquired using an Orca ER CCD camera (Hamamatsu Photonics).

Mechanical stimulation of corneal TG neuron cell bodies was performed using a heat-closed glass pipette driven by a MM3A-LS piezoelectric micromanipulator (Kleindiek Nanotechnik). The pipette was positioned on a cell body at a $45-60^{\circ}$ angle to the horizontal plane and opposite to the recording pipette, and it was moved at $540 \mu \mathrm{m} / \mathrm{s}$. A series of mechanical steps in $1 \mu \mathrm{m}$ increments were applied for $250 \mathrm{~ms}$ every $10 \mathrm{~s}$.

Mechanically activated currents were classified by their inactivation time course, which were adjusted to a monoexponential or double-exponential function using the Clampfit 10 software (Molecular Devices). In the case of fits to a double-exponential, the reported time constant $(\tau)$ corresponds to the component with the largest weight. Cells were classified in RA $(\tau \leq 10 \mathrm{~ms})$, IA $(10<\tau \leq 30 \mathrm{~ms})$, or SA $(\tau \geq 30 \mathrm{~ms})$ current, as described previously (Drew et al., 2002; Hu and Lewin, 2006; Coste et al., 2010; Hao and Delmas, 2010).

\section{Fluorometric calcium imaging}

DRG neurons were incubated with $5 \mu \mathrm{M}$ Fura2-AM and 0.2\% Pluronic F-127 (Thermo Fisher Scientific) in control external solution for $45 \mathrm{~min}$ at $37^{\circ} \mathrm{C}$ in a $5 \% \mathrm{CO}_{2}$ incubator. Coverslips with cultured neurons were placed in a low-volume chamber continuously perfused at $\sim 1 \mathrm{ml} / \mathrm{min}$ on an inverted microscope (model DMI 3000B, Leica). Fluorescence signals were obtained by exciting Fura2 at 340 and $380 \mathrm{~nm}$ with a Lambda 10-2 filter wheel and a LAMBDA LS xenon arc lamp (Sutter Instruments) and filtering the emitted fluorescence with a $510 \mathrm{~nm}$ long-pass filter. Images were acquired using an Orca ER CCD camera (Hamamatsu Photonics) and analyzed with Metafluor software (Molecular Devices). Increases in cytosolic $\mathrm{Ca}^{2+}$ are presented as the ratio of the emission intensities at 340 and $380 \mathrm{~nm}\left(\mathrm{~F}_{340} / \mathrm{F}_{380}\right.$; fluorescence arbitrary units). A positive calcium response was considered when the fluorescence signal $\left(\mathrm{F}_{340} / \mathrm{F}_{380}\right)$ deviated by at least four times the SD of the baseline. Experiments were performed at a temperature of $33-34^{\circ} \mathrm{C}$. Temperature was controlled by a homemade water-cooled Peltier system controlled by a feedback device.

Heat sensitivity was investigated with ramp-like temperature increments to $49 \pm 0.3^{\circ} \mathrm{C}$ from a basal temperature of $34^{\circ} \mathrm{C}$, applied in control solution. Thereafter, $100 \mathrm{~nm}$ capsaicin (CAP) was applied extracellularly to determine the chemical sensitivity to this specific TRPV1 agonist.

\section{Immunocytochemistry}

Cells. Cultured cells on coverslips (diameter, $6 \mathrm{~mm}$ ) were fixed for $10 \mathrm{~min}$ in $4 \%$ paraformaldehyde (PFA) in $0.1 \mathrm{M}$ PBS, washed three times with PBS for $10 \mathrm{~min}$ and twice with TBST $(0.5 \mathrm{M}$ Tris Base, $9 \% \mathrm{w} / \mathrm{v}$ $\mathrm{NaCl}, 0.5 \%$ Tween 20, pH 7.6) for $10 \mathrm{~min}$. Nonspecific binding sites were blocked by incubating the cells for $30 \mathrm{~min}$ in freshly made blocking solution containing TBST $1 \times, 1 \%$ BSA, and $0.25 \%$ Triton X-100. Cells were then incubated for $2 \mathrm{~h}$ at room temperature (RT) with primary antibodies. Then, cells were rinsed three times with TBST for $15 \mathrm{~min}$ and incubated for $2 \mathrm{~h}$ at RT with secondary antibodies. All the antibodies used are listed in Table 1 . The primary antibodies used were rabbit antiPiezo2 (1:200), mouse anti-class-III- $\beta$-tubulin (1:1000), and chicken anti-GFP (1:1000). The secondary antibodies used were donkey anti-rabbit IgG Alexa Fluor 555 (1:1000), goat anti-mouse IgG Alexa Fluor 488 (1:1000), and goat anti-chicken IgG Alexa Fluor 647 (1:1000). Both primary and secondary antibodies were diluted in blocking solution. Coverslips were mounted on a microscope slide using VECTASHIELD antifade mounting medium (H-1000, Vector Laboratories), sealed with clear nail polish and stored at $4^{\circ} \mathrm{C}$ until used. Images were acquired with an UPlanSApo $20 \times$ objective using an inverted confocal microscope (model FV1200, Olympus) driven by FV10-ASW 4.2 software (Olympus Life Sciences).

Cell identification. To identify the molecular phenotype of the electrophysiologically recorded neurons, immunocytochemistry was directly performed from cells on coverslips, immediately after recording. A line pattern was engraved on the coverslip surface before cell seeding, using a tungsten carbide pencil, to be used later as a guide in the identification of the recorded neurons. Recorded cells were identified by comparing the images obtained under transmitted light (differential interference contrast) immediately after electrophysiological recording and after Piezo2 immunostaining. In some cases, the precise location of the neuron on the coverslip was indicated by the broken tip of the recording pipette, left very close to the cell, and viewed in bright field.

\section{Immunohistochemistry}

Mice were killed by cervical dislocation and were decapitated. The cranium was opened, the TG were removed and immediately fixed in $4 \%$ PFA for $2 \mathrm{~h}$ at $4^{\circ} \mathrm{C}$, washed twice with $0.1 \mathrm{M}$ PBS, and cryoprotected in $30 \%$ sucrose overnight at $4^{\circ} \mathrm{C}$. The next day, tissues were cryopreserved in optimal cutting temperature compound (O.C.T.; Tissue-Tek), frozen in dry ice, and cryosectioned at $20 \mu \mathrm{m}$ in an axial plane (see Fig. $5 D$ ) using a cryostat (MNT, Slee Medical) and picked up in Superfrost microscope slides (Thermo Fisher Scientific). 
Table 1. Primary and secondary antibodies and RNAscope probe used

\begin{tabular}{|c|c|c|}
\hline Antibodies and RNAscope probe & Vendor & Catalog \# \\
\hline \multicolumn{3}{|l|}{ Primary antibodies } \\
\hline Rabbit anti Piezo2 & Novus Biologicals, Centennial, CO & NBPI-78624 \\
\hline Mouse anti-neuronal class III $\beta$-tubulin & BioLegend, San Diego, CA & 801201 \\
\hline Chicken anti-GFP & Abcam, Cambridge, MA & ab13970 \\
\hline Goat anti-TRPV1 & Neuromics, Edina, MN & GT15129 \\
\hline \multicolumn{3}{|l|}{ Secondary antibodies } \\
\hline Donkey anti-rabbit lgG Alexa Fluor 555 & Abcam, Cambridge, MA & ab150078 \\
\hline Donkey anti-rabbit IgG Alexa Fluor 647 & Invitrogen, Thermo Fisher Scientific, Eugene, OR & A31573 \\
\hline Goat anti-mouse lgG Alexa Fluor 488 & Invitrogen, Thermo Fisher Scientific, Eugene, OR & A11029 \\
\hline Goat anti-chicken IgG Alexa Fluor 647 & Invitrogen, Thermo Fisher Scientific, Eugene, OR & A21449 \\
\hline Goat anti-chicken IgG Alexa Fluor 488 & Invitrogen, Thermo Fisher Scientific, Eugene, OR & A11039 \\
\hline Goat anti-chicken IgG Alexa Fluor 555 & Invitrogen, Thermo Fisher Scientific, Eugene, OR & A21437 \\
\hline Goat anti-rabbit lgG Alexa Fluor 647 & Invitrogen, Thermo Fisher Scientific, Eugene, OR & A32733 \\
\hline Donkey anti-goat IgG Alexa Fluor 647 & Abcam, Cambridge, MA & ab105131 \\
\hline Goat anti-mouse lgG Alexa Fluor 555 & Invitrogen, Thermo Fisher Scientific, Eugene, OR & A32727 \\
\hline Goat anti-rabbit IgG Alexa Fluor 488 & Invitrogen, Thermo Fisher Scientific, Eugene, OR & A11008 \\
\hline RNAscope probe & ACDBio & 400191 \\
\hline
\end{tabular}

The slides containing the sections were dried in an oven at $37^{\circ} \mathrm{C}$ for $30 \mathrm{~min}$ and washed twice with $0.1 \mathrm{M}$ phospahte buffer with Tween 20 (PBT), pH 7.4 (0.0774 M Na $\mathrm{HPO}_{4}, 0.0226 \mathrm{M} \mathrm{NaH} \mathrm{PO}_{4}, 0.05 \%$ Tween 20) at room temperature. Slides were then boiled for $20 \mathrm{~min}$ in citrate buffer (citric acid $1 \mathrm{M}$, sodium citrate $1 \mathrm{M}, \mathrm{pH}$ ) ) using a water bath and cooled down for $10 \mathrm{~min}$ by stopping the bath heater. Following two additional washes with $0.1 \mathrm{M}$ PBT, tissues were incubated for $1 \mathrm{~h}$ at room temperature in a blocking solution containing 5\% BSA and $1 \%$ Triton $\mathrm{X}-100$ in PBT. Tissues were then incubated with primary antibodies overnight at $4^{\circ} \mathrm{C}$. Next, tissue sections were washed in PBT four times for $15 \mathrm{~min}$ at room temperature and incubated with secondary antibodies for $2 \mathrm{~h}$ at room temperature. Then, samples were washed four times in PBT for $15 \mathrm{~min}$, once in PBS for $10 \mathrm{~min}$, and once in distilled $\mathrm{H}_{2} \mathrm{O}$ for $5 \mathrm{~min}$. Then, slides were dried in darkness and mounted in coverslips using Fluoromount mounting medium (Sigma-Aldrich). The primary antibodies used were rabbit anti-Piezo2 (1:200), mouse anti-class-III$\beta$-tubulin (1:1000), and chicken anti-GFP (1:1000). The secondary antibodies used were donkey anti-rabbit IgG Alexa Fluor 555 (1:1000), donkey anti-rabbit IgG Alexa Fluor 647 (1:1000), goat anti-mouse IgG Alexa Fluor 488 (1:1000), and goat anti-chicken IgG Alexa Fluor 647 (1:1000). Primary and secondary antibodies were diluted in blocking solution and are listed in Table 1.

The anti-Piezo2 antibody has been used in previous studies (FlorezPaz et al., 2016; Nencini and Ivanusik, 2017; Prato et al., 2017). However, we further validated its specificity by performing immunohistochemistry in DRG and TG slices from Piezo2GFP-Cre mice following the same procedure and antibodies described above. We performed triple immunohistochemistry with anti-Piezo2, anti-GFP, and anti-classIII- $\beta$-tubulin antibodies in mouse DRG and TG slices. The analysis showed that $91.4 \pm 3.1 \%$ of the Piezo2 ${ }^{+}$DRG neurons were also GFP ${ }^{+}$ and that $90.6 \pm 3.3 \%$ of the $\mathrm{GFP}^{+}$neurons were Piezo2 ${ }^{+}$(617 DRG neurons from three slices, 1 mouse). The average Pearson correlation coefficient was $0.87 \pm 0.03$. Likewise, Piezo2 expression was observed in $90.6 \pm 8.8 \%$ of TG neurons that were $\mathrm{GFP}^{+}$, while $89.2 \pm 1.5 \%$ of the $\mathrm{GFP}^{+}$neurons were Piezo2 ${ }^{+}$(1587 neurons from $n=4$ slices, 2 mice). In this case, the average Pearson correlation coefficient was $0.81 \pm 0.01$ (data not shown).

In situ hybridization

RNAscope in situ hybridizations for freshly frozen tissue were performed according to the manufacturer instructions (ACDBio; Table 1). The Piezo2 probe was tested in TG slices of adult wild-type littermates and Piezo $2^{c K O}$ mice. Slices of $20 \mu \mathrm{m}$ were cryosectioned in O.C.T. and stored at $-80^{\circ} \mathrm{C}$. Sections were thawed just before staining and fixed with $4 \%$ PFA for 15 min followed by rinsing in PBS. All sections were mounted with Fluoromount Mounting Medium (Sigma-Aldrich).
Image analysis

Confocal image acquisition and mosaic stitching of cultured cells and TG slices was done with a UPlanSApo $20 \times$ objective using an inverted confocal microscope (model FV1200, Olympus) driven by FV10-ASW 4.2 software (Olympus Life Sciences). Images were analyzed with FIJI software (Image $1.4, \mathrm{NIH}$ ). Adjustments in brightness and contrast were done for image presentation, but all analyses and quantifications were performed on raw unprocessed data.

Immunochemistry. For Piezo $2^{+}$cell identification, regions of interest (ROIs) were manually drawn for each neuron using the $\beta$-III-tubulinlabeled image as a reference, and the mean intensity of each ROI was measured. Neurons with an intensity value $\geq 30 \%$ of the maximum measured ROI intensity were considered positive for each individual experiment. Comparison of the number of Piezo $2^{+}$neurons in WT and Piezo ${ }^{c K O}$ mice was done using samples processed in parallel, and the fluorescence of the most intense ROI in the WT was used as the maximum. For GFP immunostaining, neurons with an intensity $\geq 10 \%$ of the maximum were considered positive.

In situ hybridization. Several ROIs containing neurons were defined per slice using DAPI fluorescence and transmitted light images as a reference. A ROI, not including neurons per slice, was used to correct for a nonspecific signal. The averaged Piezo2 transcript fluorescence intensity for wild-type and Piezo $2^{c K O}$ mice was calculated as the summation of the integrated intensity from each ROI divided by the total area analyzed.

\section{Cornea immunohistochemistry}

Immunohistochemistry on whole-mounted corneas. Whole-mounted corneas immunohistochemistry was performed as described previously (Alcalde et al., 2018). Briefly, adult mice were killed by cervical dislocation followed by decapitation. Eyes were enucleated and fixed for $2 \mathrm{~h}$ at RT in methanol and DMSO (4:1), rehydrated, and washed three times in PBS $(3 \times 15 \mathrm{~min})$. The corneas were isolated and cut into quadrants, then were incubated overnight at $4^{\circ} \mathrm{C}$ in blocking solution containing $1 \%$ bovine serum albumin and $10 \%$ normal goat serum (both from Vector Laboratories) in PBS with 1\% Triton X-100 (PBS-TX). Next, corneas were incubated during $4 \mathrm{~d}$ at $4^{\circ} \mathrm{C}$ with the primary antibodies, $2 \mathrm{~d}$ in the case of the anti-TRPV1 antibody, and after washing three times in PBS-TX (15 min), the secondary antibodies were applied for $2 \mathrm{~h}$ at room temperature and then washed with PBS for $15 \mathrm{~min}$. Nuclei were counterstained using Hoechst 33342 stain $(10 \mu \mathrm{m} / \mathrm{ml}$; Thermo Fisher Scientific). Immediately afterward, corneas were washed in PBS and mounted on a coverslip with fluorescence mounting medium (DAKO).

Primary antibodies used included chicken anti-GFP (1:500), rabbit anti-Piezo2 (1:50), goat anti-TRPV1 (1:100) and mouse anti-neuronal class III- $\beta$-tubulin (1:500; Table 1$)$. The secondary antibodies were goat anti-chicken IgG Alexa Fluor 488, goat anti-rabbit IgG Alexa Fluor 647, 
donkey anti-goat IgG Alexa Fluor 647, goat anti-mouse IgG Alexa Fluor 555, and goat anti-rabbit IgG Alexa Fluor 488 (Table 1). All secondary antibodies were used at a 1:500 concentration.

Corneal slices. As described above, mice were killed by cervical dislocation followed by decapitation. Eyeballs were enucleated and fixed for $2 \mathrm{~h}$ at RT in methanol and DMSO (4:1), rehydrated, and washed three times in PBS $(3 \times 15 \mathrm{~min})$. Eyes were then cryoprotected overnight at $4^{\circ} \mathrm{C}$ in $30 \%$ sucrose in PBS, embedded in O.C.T. medium (Sakura Finetek) and rapidly frozen in isopentane. Blocks were cut on a cryostat microtome in serial $20-\mu \mathrm{m}$-thick sections and mounted on Superfrost Plus Slides. Tissue sections were washed in PBS containing 0.1\% Triton X-100 for $10 \mathrm{~min}$ and blocked for $30 \mathrm{~min}$ in PBS containing $10 \%$ goat serum at RT and incubated overnight at $4^{\circ} \mathrm{C}$ with primary antibodies diluted in PBS. Afterward, sections were washed five times for $5 \mathrm{~min}$ $(5 \times 5 \mathrm{~min})$ with PBS and incubated for $2 \mathrm{~h}$ at RT with secondary antibodies. Thereafter, sections were washed $(5 \times 5 \mathrm{~min})$ in PBS and incubated with Hoechst 33342 stain for $10 \mathrm{~min}$ at RT and rinsed $(5 \times 5 \mathrm{~min})$. Slides were then mounted with fluorescence mounting medium (DAKO). We used the same primary and secondary antibodies that were used for corneal whole-mount immunostaining.

Corneal image acquisition. Fluorescence image stacks were collected using a laser-scanning confocal microscope (model LSM 880, Zeiss) with an objective LD LCI Plan-Apochromat $25 \times / 0.8 \mathrm{Imm}$ differential interference contrast (DIC) or Plan-Apochromat $63 \times / 1.4$ Oil DIC (Carl Zeiss). Confocal images were analyzed using FIJI image analysis software (Image J 1.4, NIH). Whole-mounted corneas were divided into four quadrants, and the penetration points of subepithelial bundles through the basal lamina were counted throughout the total area of the cornea of each quadrant and were expressed as penetrations points per square millimeter.

Extracellular recordings from corneal nerve terminals

Recordings of single corneal nerve terminals in vitro were done as previously described in detail (González-González et al., 2017). Briefly, mice were killed by cervical dislocation followed by decapitation, and the excised eyes were placed in a recording chamber continuously perfused with a saline solution containing the following (in $\mathrm{mm}$ ): $128 \mathrm{NaCl}$, $5 \mathrm{KCl}, 1 \mathrm{NaH}_{2} \mathrm{PO}_{4}, 26 \mathrm{NaHCO}_{3}, 2.4 \mathrm{CaCl}_{2}, 1.3 \mathrm{MgCl}_{2}$, and 10 glucose. The solution was bubbled with $5 \% \mathrm{CO}_{2}$ and $95 \% \mathrm{O}_{2}$ and maintained at $34^{\circ} \mathrm{C}$. By using a manual micromanipulator MM33 (BioLogic), a glass micropipette electrode filled with saline solution was placed in contact with the corneal surface. Thereafter, light suction was applied on the pipette to obtain a high-resistance seal with the corneal surface, thus allowing the recording of extracellular nerve terminal impulses (NTIs) generated from single nerve corneal endings. NTIs were amplified with an AC amplifier (Neurolog NL104, Digitimer) filtered at $10 \mathrm{kHz}$ and stored in a computer, using a CED Micro1401 interface and Spike 2 software (both from Cambridge Electronic Design).

To explore the nerve activity of the entire cornea, the recording pipette was placed at sequential points on the corneal surface in a specific pattern (González-González et al., 2017). If no NTIs were detected 2 min after positioning the pipette on the corneal surface, mechanical stimulation was applied by forward displacement of the pipette of $200 \mu \mathrm{m}$ for $5 \mathrm{~s}$. If no spontaneous activity or responses to mechanical stimulation were recorded, the electrode was moved to the next recording spot. If the terminal displayed spontaneous activity or the stimulus-evoked NTIs, cold and mechanical stimuli were sequentially applied. Cold stimulation was performed first, by decreasing the baseline temperature $\left(\sim 34^{\circ} \mathrm{C}\right.$ to $\left.\sim 12^{\circ} \mathrm{C}\right)$, generating a cooling ramp lasting $\sim 35 \mathrm{~s}$ at a cooling rate of $\sim 0.6^{\circ} \mathrm{C} / \mathrm{s}$, returning thereafter to the baseline temperature. Mechanical stimulation was applied again by forward displacements of 100 and $200 \mu \mathrm{m}$ of the pipette for $5 \mathrm{~s}$ each one, with a resting period of $10-30 \mathrm{~s}$ between them. After a resting period of $2 \mathrm{~min}$, the heating stimulus was applied by increasing the temperature of the perfusion solution from $34^{\circ} \mathrm{C}$ to $\sim 50^{\circ} \mathrm{C}$ at $0.5^{\circ} \mathrm{C} / \mathrm{s}$ and returned to $34^{\circ} \mathrm{C}$. The heating ramp was applied for $\sim 30 \mathrm{~s}$. Following a resting period of $5 \mathrm{~min}$, another mechanical stimulation was performed to verify whether or not the absence of responses to heat were because of desensitization or loss of the recording. The parameters analyzed were as follows: the background activity, defined as the mean basal ongoing frequency in impulses per second at the basal temperature $\left(\sim 34^{\circ} \mathrm{C}\right)$, was measured during the $30 \mathrm{~s}$ period that preceded the onset of the first stimulus; the general activity, assessed by the number of times that the pipette was placed on the corneal surface and some activity was detected compared with the total number of times that the pipette was placed, and the number of NTIs during the mechanical stimulation and during the cooling and heating ramp. Mechanical response was assessed as the increment in NTIs during mechanical stimulation ( $5 \mathrm{~s}$ ) with respect to the total number of NTIs fired during the $5 \mathrm{~s}$ period immediately before mechanical stimulation. A positive response to mechanical stimulation was considered when the increment in the NTIs during mechanical stimulation is, at least, $50 \%$ of the terminal background activity for the same period of time.

\section{Behavior}

Cotton swab assay. To assess deficits in light touch, the paw withdrawal evoked by a cotton swab was used (Garrison et al., 2012). In brief, mice were placed in an elevated mesh-like platform of square holes in an $\sim 5 \times 5 \mathrm{~mm}$ grid (Hugo Basile). Mice were acclimated for $1 \mathrm{~h}$ before testing. A frayed cotton swab was swept five times to each plantar surface of the hindpaw for $1 \mathrm{~s}$, with $10 \mathrm{~s}$ between each hindpaw sweep. The number of withdrawals was recorded and analyzed as a proportion of positive responses with respect to the total number of trials. The experimenter was blinded to mouse genotype throughout the data collection and analysis.

Assessment of blinking. Adult male and female mice, Piezo ${ }^{2 c K O}$ and their littermates, were carefully held by the scruff to apply gentle touch to the cornea with von Frey filaments. Filaments of 0.008 and $0.02 \mathrm{~g}$ were tested in each eye 5-10 times every $5 \mathrm{~s}$ in the morning $(0.008 \mathrm{~g})$ and afternoon (0.02 g) sessions, alternating the left and right eyes, on 3 consecutive days. The procedure was recorded using a Grasshopper3 GS3-U3-32S4M camera (Point Gray) at 15 frames/s. One hundred twenty-six videos were visualized in slow motion by two observers, and the number of blinks associated with the monofilament touch were counted. Data are presented as the mean proportion of evoked responses with regard to the total number of trials. Thicker filaments were also tested $(0.04$ and $0.4 \mathrm{~g})$ but after the first touch most of the animals moved vigorously as the filament approached, preventing the analysis of their blinking. Three of the tested Piezo $2^{c K O}$ mice closed their eye after the first touch; these animals were not included in the analysis.

\section{Reagents}

Capsaicin (8-methyl- $N$-vanillyl-trans-6-nonenamide; Sigma-Aldrich) was prepared in ethanol as a stock $(100 \mathrm{~mm})$ and stored at $-20^{\circ} \mathrm{C}$.

\section{Statistical and data analysis}

Data are expressed as the mean \pm SEM. Differences were considered significant at $* p<0.05, * * p<0.01$, and $* * * p<0.001$. Exact $p$ values, statistical test, and sample size are indicated in the text or in figure legends. Student's $t$ test, Mann-Whitney rank-sum test, and $Z$-test were performed using the SigmaStat 4.0 software (Systat Software). The OriginPro 2019 software (OriginLab) was used for graphing.

\section{Results \\ A large fraction of TG corneal neurons exhibit mechanosensitivity}

We identified, using epifluorescence illumination, the cell bodies of intact (Fig. 1A, left) and cultured TG corneal neurons (Fig. $1 A$, right), retrogradely labeled with FM 1-43FX applied to the eye surface in adult wild-type mice, and performed patch-clamp recordings on their somas. As expected, retrogradely labeled cells were found in the ophthalmic branch of the TG.

In a fraction of these neurons, sustained cell membrane indentation, conducted with an electrically driven glass probe, evoked MA currents showing graded increases in amplitude in response to progressively larger indentation values (Fig. 1B). MA currents were evoked in 115 of the 275 wild-type corneal TG 
A

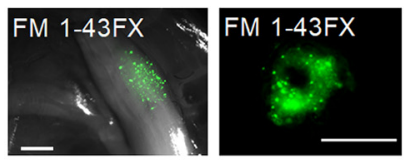

B

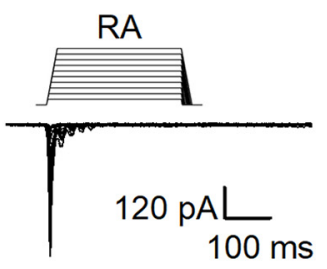

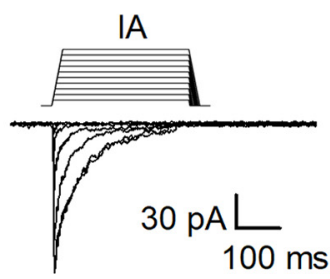

E

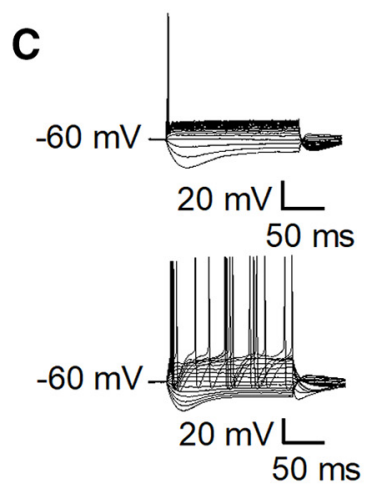

F

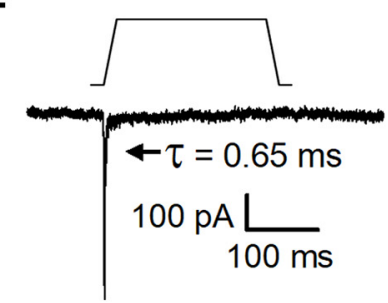

H

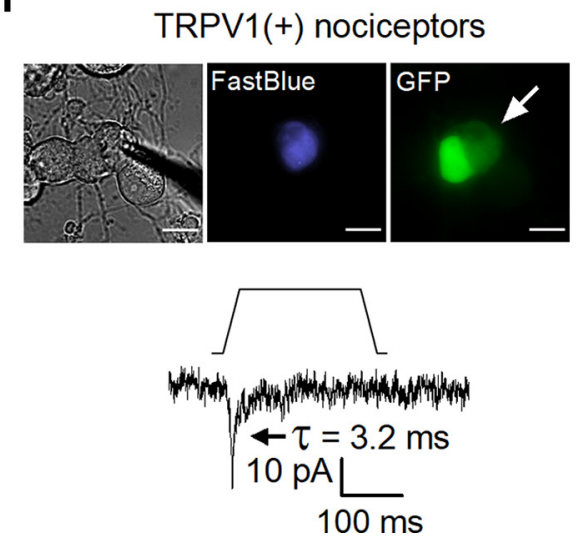

D

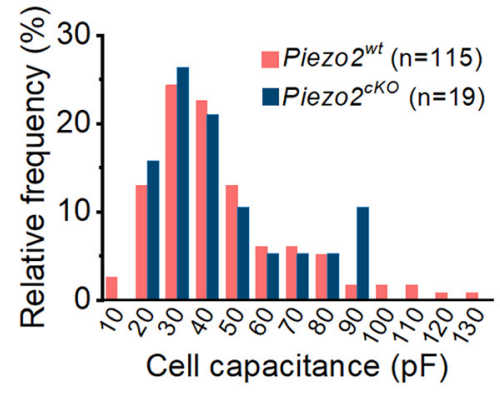

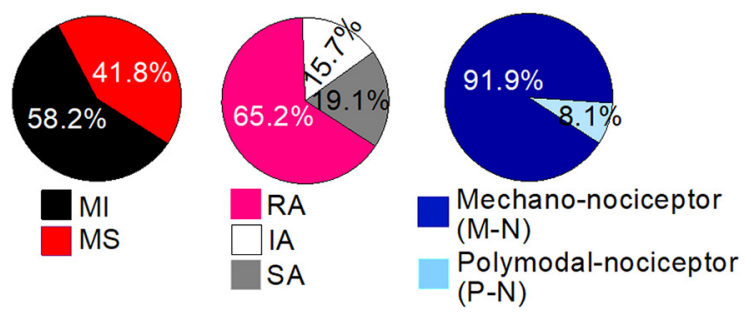

(P-N)

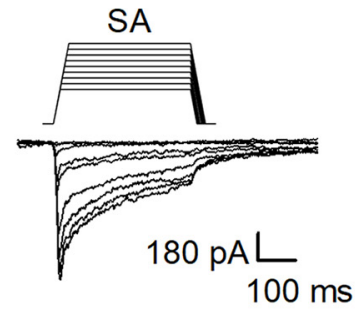

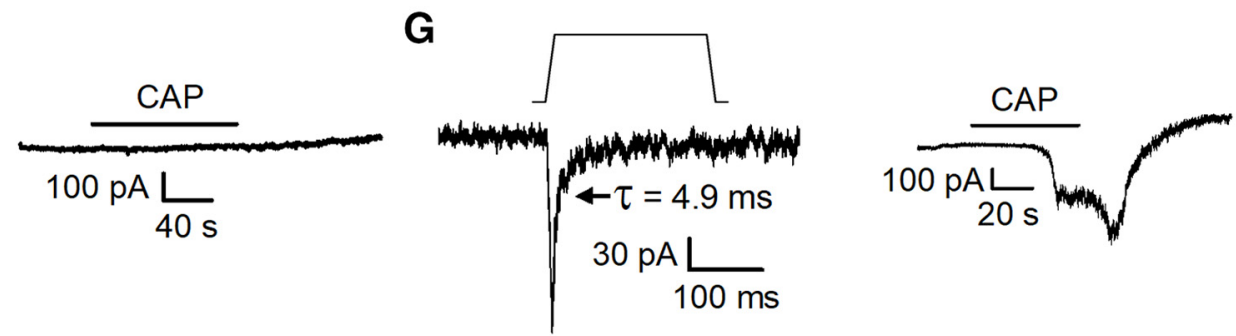

\section{I}

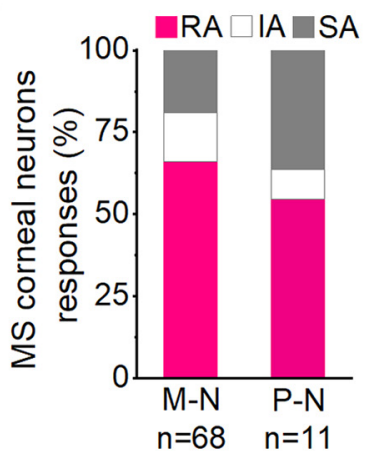

J

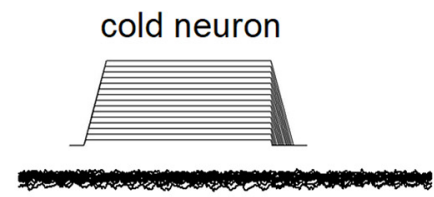

$50 \mathrm{pA}$

Figure 1. Mechanically activated currents in trigeminal corneal neurons. A, FM 1-43 FX fluorescent labeling of TG ganglia in fresh tissue (left) and of TG cultured cells (right) after its application to the corneal surface. Scale bars: left, $500 \mu \mathrm{m}$; right, $25 \mu \mathrm{m}$. B, Representative whole-cell recordings in the voltage-clamp configuration $\left(V_{\text {hold }}=\right.$ $-60 \mathrm{mV}$ ) of the three general subtypes of mechanically activated currents, RA, IA, and SA, recorded from cultured corneal TG neurons identified by FM 1-43 FX labeling. Mechanical stimuli in $1 \mu \mathrm{m}$ increments are indicated on top of each recording. Time constants of current relaxation are indicated in each panel. $\boldsymbol{C}$, Representative whole-cell recordings in current-clamp configuration showing the phasic $(n=62$, top) and tonic ( $n=9$, bottom) firing pattern of corneal TG neurons. $\boldsymbol{D}$, Frequency histogram of cell capacitance shows that TG mechanically activated neurons are mainly of small and medium size and that the size distribution was similar for wild-type (pink) and Piezo2 $2^{\text {cKO }}$ mice (blue). $\boldsymbol{E}$, Pie plots showing the distribution of mechano-sensitive (MS) (115 of 275) and mechano-insensitive (MI) corneal TG neurons (160 of 275; left); the proportion of the different types of mechanically activated currents is displayed with respect to the total number of MA recorded neurons $(n=115$; central pie plot) and the distribution of the pure mechano-nociceptor (M-N; 68/74) and polymodal nociceptor (P-N; 6/74; right) neurons. $F$, G, Representative recordings of RA mechanically activated whole-cell currents $\left(V_{\text {hold }}=-60 \mathrm{mV}\right)$ of corneal neurons in response to mechanical indentation (left panels) and to $100 \mathrm{~nm}$ capsaicin (right panels). Mechanical stimuli of $250 \mathrm{~ms}$ duration are indicated on top of the recordings ( $11 \mu \mathrm{m}$ and $7 \mu \mathrm{m}$ respectively). $\boldsymbol{H}$, Phase-contrast image (left) of a Fast Blue-labeled corneal neuron (middle) expressing TRPV1 (right, arrow), identified by the expression of GFP. Note that GFP labels two adjacent neurons. Scale bars, $25 \mu \mathrm{m}$. The bottom panel shows the whole-cell current response of the labeled neuron in the top panels to mechanically indentation $(15 \mu \mathrm{m})$. The patch electrode in the phase-contrast image indicates the recorded neuron. $I$, Comparison of the proportions of MS corneal neurons responding with RA, IA, and SA currents in M-N $(n=68)$ versus P-N $(n=11) ; p=0.682$ (RA), $p=0.0 .977$ (IA), and $p=0.370$ (Ztest). $J$, Representative traces of a whole-cell recording in the voltage-clamp configuration $\left(V_{\text {hold }}=-60 \mathrm{mV}\right.$ ) of a TRPM8-expressing cold-sensitive cultured corneal TG neuron identified by the expression of EYFP, showing the absence of a response to mechanical indentation. The mechanical stimulus in $1 \mu \mathrm{m}$ increments is indicated on top of the recording. Time constants $(\tau)$ of MA current inactivation are indicated for each panel. 
Table 2. Passive membrane properties of retrogradely labeled corneal neurons

\begin{tabular}{|c|c|c|c|c|c|c|c|}
\hline & & $\begin{array}{l}\text { Membrane } \\
\text { potential } \\
(\mathrm{mV})\end{array}$ & $\begin{array}{l}\text { Rheobase } \\
\text { (pA) }\end{array}$ & $\begin{array}{l}\text { Input resistance } \\
(\mathrm{M} \Omega)\end{array}$ & Mechanical threshold ( $\mu \mathrm{m})$ & $\begin{array}{l}\text { Current amplitude } \\
(\mathrm{pA} / \mathrm{pF})\end{array}$ & $\begin{array}{l}\text { Cell capacitance } \\
(\mathrm{pF})\end{array}$ \\
\hline \multirow[t]{3}{*}{ WT } & RA & $\begin{array}{c}-61.5 \pm 1.4 \\
(n=75)\end{array}$ & $\begin{array}{r}407 \pm 36 \\
\quad(n=45)\end{array}$ & $\begin{array}{r}89.1 \pm 9.8 \\
(n=71)\end{array}$ & $\begin{array}{l}6 \pm 0.3 \\
(n=75)\end{array}$ & $\begin{array}{r}7.4 \pm 1.4 \\
(n=75)\end{array}$ & $\begin{array}{r}40 \pm 2.6 \\
(n=75)\end{array}$ \\
\hline & IA & $\begin{array}{c}-65.7 \pm 1.5 \\
(n=18)\end{array}$ & $\begin{array}{l}486 \pm 86 \\
\quad(n=10)\end{array}$ & $\begin{array}{c}88.5 \pm 18.6 \\
(n=18)\end{array}$ & $\begin{array}{l}6.6 \pm 0.8 \\
\quad(n=18)\end{array}$ & $\begin{array}{r}6.7 \pm 1.9 \\
(n=18)\end{array}$ & $\begin{array}{r}43.7 \pm 6.4 \\
(n=18)\end{array}$ \\
\hline & SA & $\begin{array}{c}-62.9 \pm 1.7 \\
(n=22)\end{array}$ & $\begin{array}{l}401 \pm 59 \\
\quad(n=15)\end{array}$ & $\begin{array}{c}104 \pm 23.5 \\
(n=22)\end{array}$ & $\begin{array}{l}5.6 \pm 0.6 \\
\quad(n=22)\end{array}$ & $\begin{array}{c}15.9 \pm 3.8 * \\
(n=22)\end{array}$ & $\begin{array}{r}39.2 \pm 5.8 \\
(n=22)\end{array}$ \\
\hline \multirow[t]{3}{*}{ Piezo2 $2^{\text {cKO }}$} & RA & $\begin{array}{c}-58.4 \pm 2.9 \\
(n=14)\end{array}$ & $\begin{array}{r}401 \pm 85 \\
(n=8)\end{array}$ & $\begin{array}{r}56.1 \pm 5.9 \\
(n=14)\end{array}$ & $\begin{array}{r}3.9 \pm 0.9 \# \\
(n=14)\end{array}$ & $\begin{array}{r}5.8 \pm 1.6 \\
(n=14)\end{array}$ & $\begin{array}{l}39.9 \pm 6 \\
\quad(n=14)\end{array}$ \\
\hline & $\mathrm{IA}$ & $-81.1(n=1)$ & $322(n=1)$ & $40(n=1)$ & $11(n=1)$ & $2.3(n=1)$ & $21.3(n=1)$ \\
\hline & SA & $\begin{array}{c}-60.8 \pm 5.4 \\
(n=4)\end{array}$ & $355(n=1)$ & $\begin{array}{c}55.3 \pm 12.6 \\
(n=4)\end{array}$ & $5.5 \pm 1.5(n=4)$ & $\begin{array}{c}6.7 \pm 3.8 \\
(n=4)\end{array}$ & $\begin{array}{c}47.4 \pm 12.5 \\
(n=4)\end{array}$ \\
\hline
\end{tabular}

Electrical properties of mechanosensitive corneal neurons from wild-type and Piezo $2^{c K O}$ mice. Mean \pm SE values are given for each parameter. Membrane potential values were adjusted for the calculated liquid junction potential of $+12 \mathrm{mV}$. To compare the means of different parameters among the three types of MA cells, the Kruskal-Wallis one-way ANOVA on ranks test and the Dunn's method one-way ANOVA test were used.

*Density of current in SA cells is significantly higher than in RA cells in wild-type mice $(p=0.037)$. To compare the means of different parameters for each type of cell between wild-type and Piezo2 ${ }^{c K O}$ mice, the Student's $t$ test and Mann-Whitney rank-sum test were used.

\#The mechanical threshold in RA cells from Piezo2 ${ }^{c K O}$ mice is lower than in RA cells from wild-type mice $(p=0.013)$. The absence of symbols indicates the lack of significant differences.

neurons explored (Fig. 1E, left pie plot). MA currents were further classified as RA, IA, and SA, based on their inactivation time course (Hu and Lewin, 2006; Coste et al., 2010; Fig. 1B,E, central pie plot). Almost two-thirds were RA. Injection of current pulses on corneal MA neurons generally evoked phasic action potential firing (62 of 71; Fig. $1 C$, top), with only a few neurons showing a tonic firing pattern ( 9 of 71 ; Fig. $1 C$, bottom). Passive membrane properties (membrane potential, rheobase, input resistance, and cell capacitance) of MA corneal TG neurons were similar to those reported in the general population of TG neurons (Cabanes et al., 2002). Parameters were analyzed for each class of mechanosensitive (MS) neuron (i.e., RA, IA, and SA); membrane potential, rheobase, input resistance, and cell capacitance were not different for the three classes. However, we did find that the peak current density was significantly higher in SA MS neurons $(15.9 \pm 3.8 \mathrm{pA} / \mathrm{pF})$ compared with RA MS neurons $(7.4 \pm 1.4 \mathrm{pA} / \mathrm{pF}$; Table 2$)$. In agreement with their capacitance values, corneal neurons are predominantly distributed within the small- to medium-sized population of TG neurons (Fig. 1D).

\section{Distinct subpopulations of corneal neurons display mechanically activated currents}

During voltage-clamp recordings performed on MA cultured corneal neurons, we observed that the majority (68 of 74) were insensitive to the application of $100 \mathrm{~nm}$ CAP, the selective agonist of TRPV 1 channels typically expressed by polymodal nociceptor neurons (Caterina et al., 1997; Tominaga et al., 1998; Fig. 1E, right pie chart, $F$ ). Thus, capsaicin insensitivity was used to define the group of pure mechano-nociceptor corneal neurons (Belmonte et al., 1991). The remaining six MA neurons, where CAP evoked an inward current, were unambiguously considered as corneal polymodal nociceptor neurons (Fig. $1 G$; Belmonte et al., 1991). The proportion of polymodal corneal neurons recorded, using this criterion, was lower than expected from previous studies in peripheral corneal nerve terminals (Chen et al., 1997; González-González et al., 2017). Thus, to rule out any possible bias in the selection of recorded neurons or a damaging effect of the mechanical stimulation, applied before the CAP application, we further characterized the polymodal nociceptor subpopulation using a transgenic mouse line expressing EGFP under the promoter of TRPV1 (TRPV1-GFP). First, using intracellular $\mathrm{Ca}^{2+}$ imaging, we examined whether GFP expression in this line is a reliable marker for the polymodal phenotype. We measured calcium responses to CAP (100 nM) and heat $\left(49 \pm 0.3^{\circ} \mathrm{C}\right)$ in Fura2-loaded cultured TG neurons. We found that $31 \%$ of them ( 27 of 87 cells) expressed the EGFP protein (Fig. 2A) and, as expected, the great majority responded to TRPV1 agonists (Fig. 2B). As shown in the representative traces of Figure $2 B$, heat and capsaicin evoked calcium increases in the three GFP-labeled TG neurons in this imaging field. In contrast, very few $\mathrm{GFP}^{-}$cells were activated by capsaicin. A summary of their calcium responses to heat or capsaicin is shown in Figure 2, $C$ and $D$, for $\mathrm{GFP}^{+}$and $\mathrm{GFP}^{-}$TG neurons, respectively. The functional data show that virtually all of the $\mathrm{GFP}^{+}$neurons were activated by CAP (96\%; Fig. 2C) while only $8 \%$ of the $\mathrm{GFP}^{-}$neurons responded to this agonist (Fig. $2 D$ ); these proportions were significantly different $(p<0.001 ; Z$-test). Moreover, the majority of $\mathrm{GFP}^{+}$neurons were activated by heat (93\%; Fig. 2C), a responsiveness that was also found in a smaller fraction of $\mathrm{GFP}^{-}$ neurons (30\%; Fig. 2D), consistent with the notion that noxious heat sensitivity in primary sensory neurons is determined by other channels in addition to TRPV1 (Vandewauw et al., 2018). Venn diagrams of these results show that almost all $\mathrm{GFP}^{+}$ responded to CAP and heat (Fig. 2C) and only 4 of 60 of the $\mathrm{GFP}^{-}$were CAP and heat sensitive (Fig. 2D). The same results were obtained using a higher concentration of CAP (200 nM; data not shown). Therefore, we conclude that GFP expression is a good proxy of TRPV1 expression in TG neurons of this transgenic mouse line, indicating that it can be used to identify TRPV ${ }^{+}$nociceptive neurons.

Next, we tested the mechanosensitivity of retrogradely labeled corneal neurons in TRPV1-GFP mice (Fig. $1 H$ ). MA currents were recorded in 5 of 51 of the $\mathrm{GFP}^{+}$corneal neurons (9.8\%), 4 of them belonging to the RA type (Fig. $1 H$ ) and 1 to the SA type. This shows that only a small fraction of the somas of corneal TRPV1-expressing nociceptors in mouse responded to mechanical indentation. For further analysis, we pooled together the results of capsaicin-activated corneal polymodal neurons recorded in the $\mathrm{C} 57 \mathrm{BL} / 6 \mathrm{~J}$ and in $\mathrm{GFP}^{+}$neurons of TRPV1-GFP mice. Pure mechano- and polymodal nociceptors displayed the three types of MA currents in different proportions, but were not significantly different (Fig. 1I). The peak current density was not different between pure mechanonociceptors $(8.6 \pm 1.4 \mathrm{pA} / \mathrm{pF} ; n=68)$ and polymodal nociceptors $(4.2 \pm 1.4 \mathrm{pA} / \mathrm{pF} ; n=11 ; p=0.248$; Student's $t$ test, MannWhitney rank-sum test). 
A
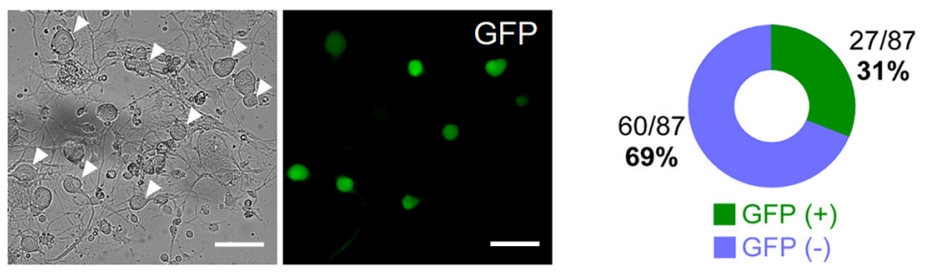

B

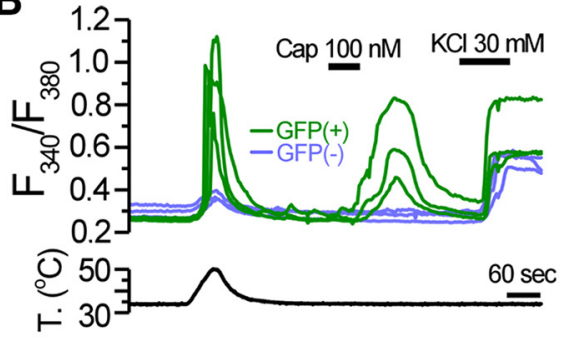

C

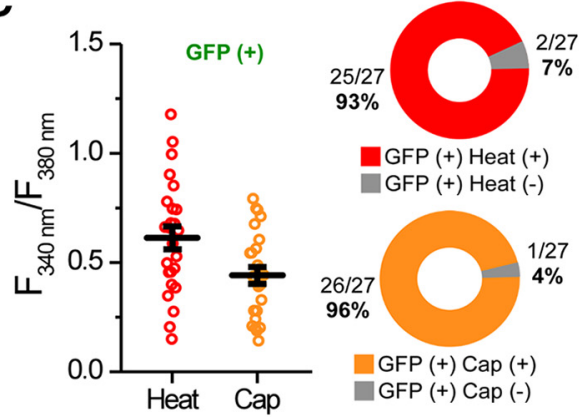

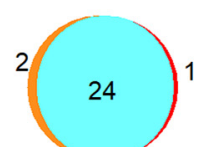

Heat (+)

Cap (+)

Heat $(+)$ Cap $(+)$
D

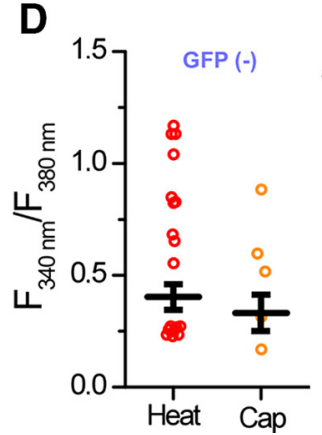

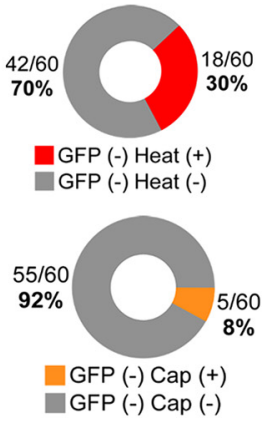

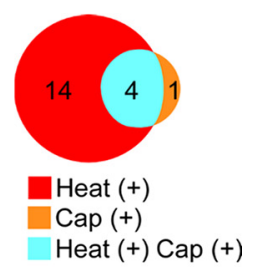

Figure 2. Functional characterization of the TRPV1-GFP transgenic mouse line. $A$, Representative transillumination (left) and GFP fluorescence (right) images of TG cultured neurons from a TRPV1-GFP mouse. Arrowheads in the left panel indicate the GFP ${ }^{+}$neurons in the right panel. Scale bar, $20 \mu \mathrm{m}$. Diagram indicates the proportion of GFP ${ }^{+}$and GFP ${ }^{-}$TG neurons from TRPV1GFP mice. $\boldsymbol{B}$, Time course of the averaged Fura2 ratio changes in cultured TG neurons during application of heat $\left(50^{\circ} \mathrm{C}\right)$ and capsaicin (Cap, $\left.100 \mathrm{~nm}\right)$; high $\mathrm{K}^{+}$was also applied to test the viability of neurons. Bottom trace represents the simultaneous recording of the bath temperature during the experiment. Green traces represent GFP ${ }^{+}$, and blue traces represent GFP ${ }^{-}$cells. $\boldsymbol{C}$, $\mathbf{D}$, Dot plot of calcium increase exhibited by individual cells in response to heat and CAP of GFP ${ }^{+}$and $\mathrm{GFP}^{-}$neurons; error bars indicate the SEM. Central diagrams show the proportion of the responses to CAP (26 of 27) and heat (25 of 27) in GFP ${ }^{+}$neurons, and to CAP (5 of 60) and heat (18 of 60) in GFP ${ }^{-}$neurons during the protocol shown in $\boldsymbol{B}$. Venn diagrams summarize the responses to heat and capsaicin, and their overlap. Results in this figure were obtained from eight independent experiments from two mice.

We also tested the effect of mechanical indentation on TG cold thermoreceptor neurons in a transgenic mouse expressing YFP under the control of the transient receptor potential melastatin 8 (TRPM8) channel promoter (Morenilla-Palao et al., 2014). None of these cold thermoreceptor neurons $(n=12)$ responded to mechanical indentation (Fig. 1J).

\section{Piezo2 is expressed in corneal mechanosensitive neurons of different submodality}

Next, we asked whether Piezo2 is expressed by the two subclasses (i.e., pure mechano-nociceptors and polymodal nociceptors) of mechanosensitive TG corneal neurons and whether the expression correlates with kinetic features of the currents. To this end, we combined recordings of MA currents, their kinetic analysis, and responses to $\mathrm{CAP}$, with subsequent immunofluorescence staining for tracking Piezo2 ${ }^{+}$corneal neurons in culture using a reliable antibody against Piezo2 (Florez-Paz et al., 2016). Immunoreactivity for Piezo2 was tested in 36 of the MA neurons previously recorded. Twenty-five were unequivocally identified as purely mechanonociceptive neurons, 8 were CAP sensitive or TRPV1-GFP ${ }^{+}$(i.e., polymodal nociceptor neurons), and 3 of them could not be classified because CAP sensitivity was not tested. Identification of the recorded neurons in the coverslip after immunohistochemistry was possible in 23 of the 36 tested neurons. Piezo 2 expression was confirmed in 18 neurons (78.2\%), 14 pure mechano-nociceptive neurons, and 1 polymodal nociceptor; 3 of them could not be subclassified further. The remaining five MA neurons (21.8\%) were Piezo2 $2^{-}$, of which four were identified as pure mechano-nociceptors and 1 as a polymodal nociceptor. These results suggest that Piezo2 is the major, but not the unique, transducer of mechanical forces in MS corneal neurons.

Piezo2 expression was more frequent in RA (85.7\%) than in IA (66.6\%) and SA (66.6\%) neurons, but differences between these proportions did not reach statistical significance $(p=0.963$ and $p=0.713$, respectively; $Z$-test; Fig. $3 H)$. These results evidence the lack of a strict correlation between Piezo2 expression and the kinetic features of the MA currents.

Figure $3 A-C$ shows examples of the indentation-induced RA, $\mathrm{SA}$, and IA currents evoked in three CAP-insensitive corneal neurons. Two of them (Fig. $3 A, B$, top panels) are immunoreactive for Piezo2 and one lacks Piezo2 (Fig. $3 C$ ). Images of the only two identified mechanosensitive polymodal nociceptive neurons, one displaying SA current that expresses Piezo2 and one RA neuron negative for Piezo2 are shown in Figure 3, $D$ and $E$, respectively. The images in Figure $3 E$ correspond to the RA neuron shown in Figure $1 G$. The lack of Piezo2 staining was not because of failure of Piezo2 labeling because Piezo2 was always visible in other neighboring neurons (Fig. 3F, arrow, $G$, asterisk).

Importantly, this analysis revealed that Piezo2 is expressed in most MS corneal neurons, basically in the pure mechano-nociceptor class $(93.3 \%, 14$ of $15 ; p<0.001$, Student's $t$ test) and mediates RA, IA, and SA current adaptation types. Our analysis also evidenced that a small population of TRPV1-GFP ${ }^{+}$corneal neurons (i.e., polymodal nociceptors responded to mechanical stimulation; 9.8\%; Fig. $1 H$ ).

Combined, these two findings suggest that most polymodal nociceptors (TRPV1 ${ }^{+}$neurons) are Piezo2-GFP ${ }^{-}$and that the majority of Piezo ${ }^{+}$neurons do not express TRPV1. To confirm this observation, we examined the immunocolocalization of Piezo2 and GFP in TRPV1-GFP mice in cultured TG ganglion neurons. Neurons were counted from a mosaic image of an entire coverslip (Fig. 4A, top left). Of $671 \mathrm{TRPV}^{+}$neurons, only 152 are labeled for Piezo2 (23\%). This proportion is somewhat higher but is in line with the proportion of corneal polymodal neurons responding to mechanical indentation (9.8\%; Fig. $1 \mathrm{H}$ ). Likewise, a low proportion of the labeled Piezo2 TG neurons were also positive for TRPV1 (18\%; 152 of 826), suggesting that 
A
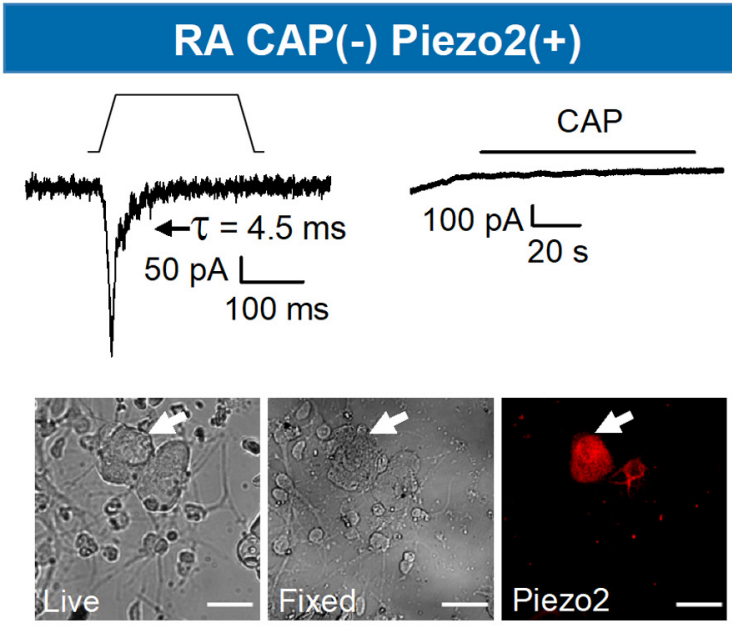

\section{C}
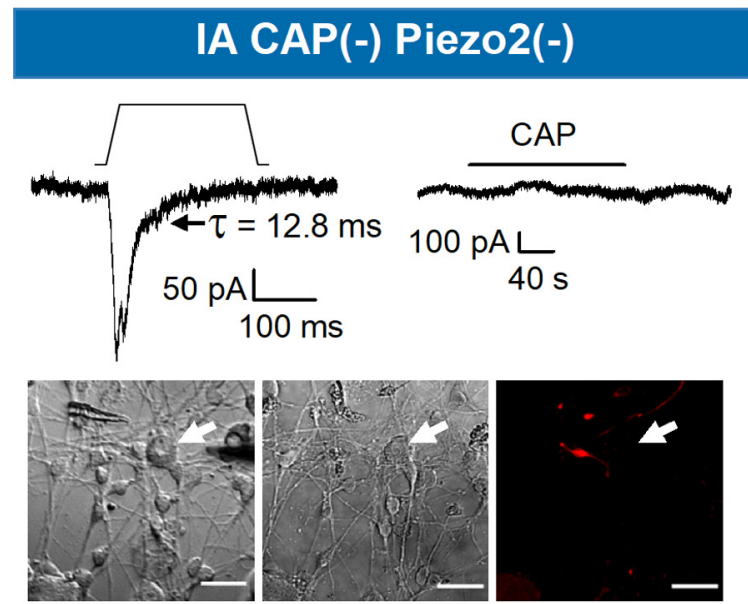

E
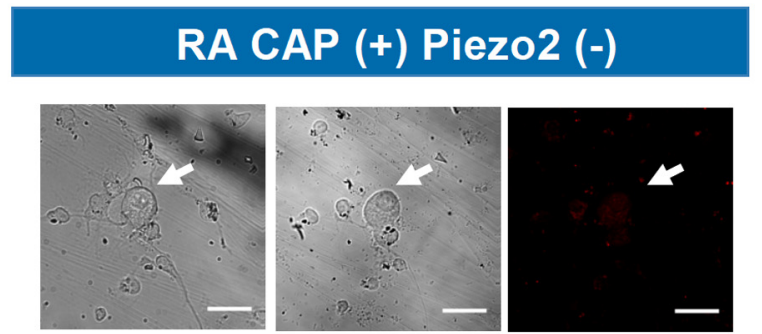

B
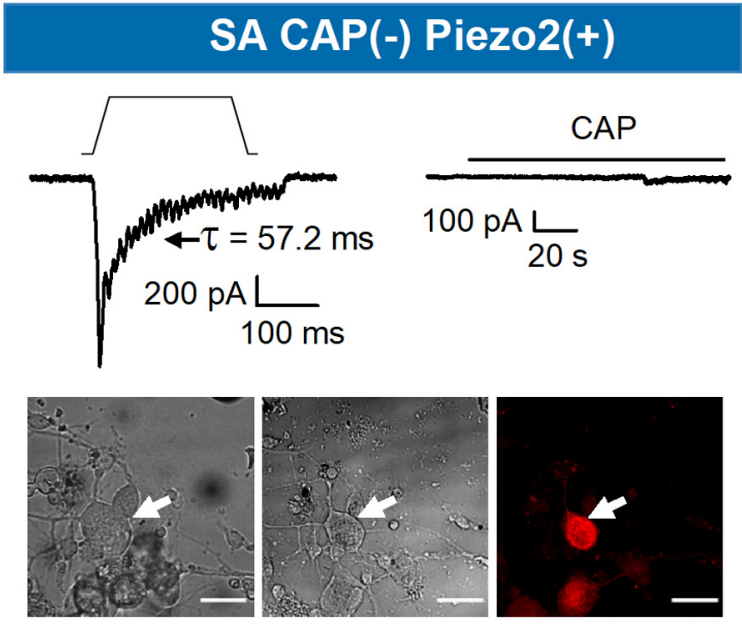

D
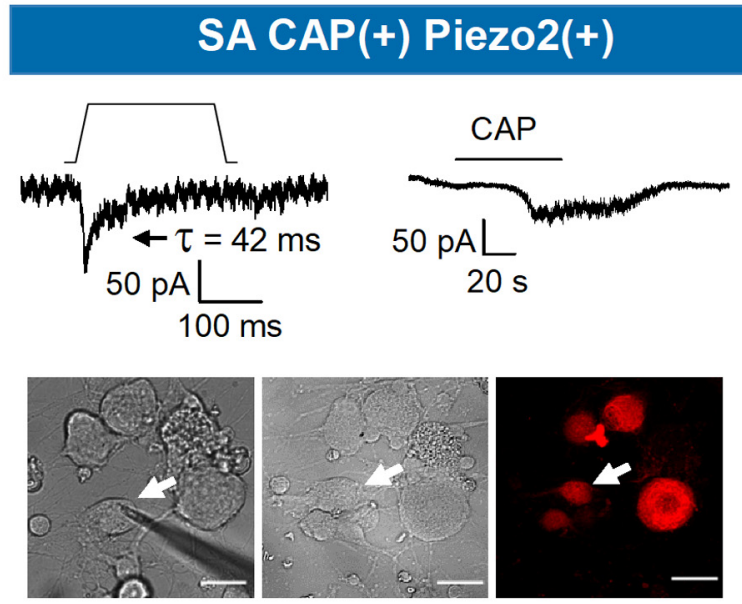

$F$
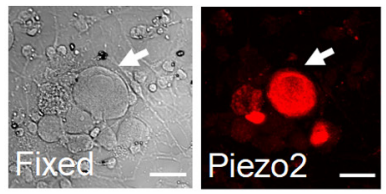

G

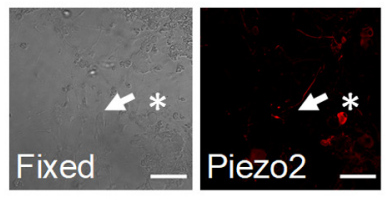

H

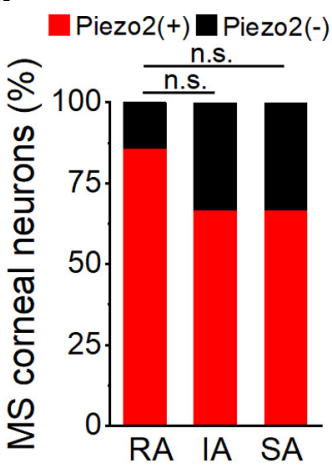

Figure 3. Piezo2 is expressed in mechanosensitive trigeminal corneal nociceptors. $\boldsymbol{A}-\boldsymbol{D}$, Representative whole-cell currents $\left(V_{\text {hold }}=-60 \mathrm{mV}\right)$ in response to static indentation, depicted on top of each recording $(15,15,12$, and $7 \mu \mathrm{m}$, respectively). Mechanical stimuli activate inward currents with different inactivation kinetics (top left panels); the type of MA current is indicated in the top label of each panel (RA, IA, SA). Top right panels show the current responses of the same neurons to $100 \mathrm{~nm}$ CAP. Bottom panels show phase-contrast images of the recorded neurons, indicated by the arrows, in live (left), fixed conditions (central) and after immunostaining for Piezo2 (right panels). Scale bars, $25 \mu \mathrm{m}$. $\boldsymbol{E}$, Phase-contrast images of the recorded neuron in Figure $1 G$, indicated by the arrow, in live (left) and fixed conditions (center), and after immunostaining for Piezo2 (right). $\boldsymbol{F}$, Piezo2 immunofluorescence was visible in neighboring neurons in another field from the same coverslip. Scale bars, $25 \mu \mathrm{m}$. G, Uncropped image of the same field shown in Figure $3 C$. Left, Phase-contrast image of the recorded neuron, indicated by the arrow in fixed conditions (left) and after immunostaining for Piezo2 (right). The asterisk points to a neighboring positive neuron for Piezo2. Scale bars, $50 \mu \mathrm{m}$. $\boldsymbol{H}$, Bar graph representing the proportion of Piezo2 ${ }^{+}$and Piezo2 ${ }^{-}$corneal neurons responding with rapidly $(n=14)$, intermediately $(n=3)$, and slowly $(n=6)$ adapting mechanically activated currents. n.s., not significant.

Piezo2 ${ }^{+}$neurons are mainly pure mechano-nociceptors. A similar low overlap for both markers was observed in DRG neurons (Coste et al., 2010). This proportion is somewhat higher than the one obtained from our functional analysis in which only 1 of the
15 (6.7\%) Piezo2 ${ }^{+}$MS corneal neurons was a polymodal nociceptive neuron. A possible explanation for these differences is that corneal polymodal neurons represent a smaller fraction within the entire population of TG neurons of such modality or 
that the expression of Piezo2 in some corneal neurons is not sufficient to evoke a recordable mechanical response.

\section{Sensory-specific genetic ablation of Piezo2}

To determine the contribution of Piezo2 to the generation of MA currents in corneal neurons, we generated a sensory-specific conditional Piezo2 knock-out $\left(\right.$ Piezo ${ }^{c K O}$ ) mouse. This allowed the selective ablation of Piezo2 channels in adult sensory neurons. To this end, we crossed floxed Piezo2 mice (Piezo ${ }^{f l f f}$; Woo et al., 2014) with an Advil-Cre mouse, a line expressing Cre recombinase under the sensory neuron-specific Advillin promoter (Zurborg et al., 2011). Immunocytochemical analysis in cultured TG neurons, identified by $\beta$-III-tubulin labeling (Fig. $5 A$ ), revealed that $58 \%$ of TG neurons of wild-type littermate mice are immnunoreactive for Piezo2 (Fig. 5A,B). Compared with wild type, Piezo2 expression was significantly reduced $(p<0.001)$ but still expressed in a significant fraction $(31.7 \%)$ of TG neurons from Piezo2 ${ }^{c K O}$ mice (Fig. 5A,B). Thus, Piezo2 was reduced by $45 \%$ compared with wild-type littermates. These results evidenced that the efficiency of Piezo2 ablation in this recombination system was incomplete, as had been shown previously (Zhang et al., 2019). Nevertheless, Piezo2 reduction was sufficient to generate an altered sensory-motor phenotype as has been described for the ablation of Piezo2 in proprioceptive sensory neurons (Ranade et al., 2014; Woo et al., 2015; Florez-Paz et al., 2016). Thus, when suspended from their tails, the position of the hindlegs in Piezo $2^{c K O}$ mice was abnormal (Fig. 5C), which is indicative of proprioceptive deficits. Compared with wild-type littermates, Piezo $2^{c K O}$ mice also presented a reduced sensitivity to light-touch stimuli when tested with a cotton swab stroke over their paws (Ranade et al., 2014; Fig. 5C, bottom).

We also examined the expression of Piezo2 in TG slices from wild-type littermates and Piezo $2^{c K O}$ mice. Slices were cut in the axial (i.e., horizontal) plane to visualize the entire TG (Fig. 5D). This is an important consideration because the TG cell bodies are somatotopically distributed in particular areas within the ganglion that may harbor different proportions of mechanosensitive neurons. Piezo 2 expression was detected in $41.7 \%$ of TG neurons from wild-type littermates (Fig. $5 D$, top panels; $n=3979$ cells, 6 slices, 3 mice) and in 20.3\% of the Piezo $2^{c K O}$ mice (Fig. $5 D$, bottom panels; $n=5884,8$ slices, 4 mice), representing a reduction of $51.3 \%$. Two immunohistochemistry experiments were performed in parallel in wild-type and Piezo $2^{\text {cKO }}$ mice that were analyzed independently. Differences in the proportions of neurons expressing Piezo2 were statistically significant for each of the two experiments ( $p<0.001, Z$-test analysis).

We additionally tested the ablation of Piezo2 in Piezo2 $2^{\text {cKO }}$ mouse by performing in situ hybridization of Piezo 2 mRNA with RNAscope technology (ACDBio). TG slices were cut in the axial plane. We compared Piezo2 transcript fluorescence from wild-type littermates ( $n=32$ regions, 4 slices, 2 mice) and Piezo2 $^{\text {cKO }}$ ( $n=33$ regions, 6 slices, 3 mice) and observed a $51.6 \%$ deletion of Piezo2 transcripts in Piezo ${ }^{c K O}$ mice (Fig. 5E). In conclusion, Piezo 2 ablation efficiency was $\sim 50 \%$ and was consistent when evaluated with the following three different approaches: immunochemistry technique in cultured cells and TG slices, and RNAscope in situ hybridization (Fig. 5F).

\section{Ablation of Piezo2 reduces the proportion of corneal neurons responding to mechanical indentation}

Next, we examined the mechanosensitivity of TG cultured corneal neurons after genetic Piezo2 ablation. Notably, the ablation of Piezo2 caused an incomplete but significant reduction in the
A

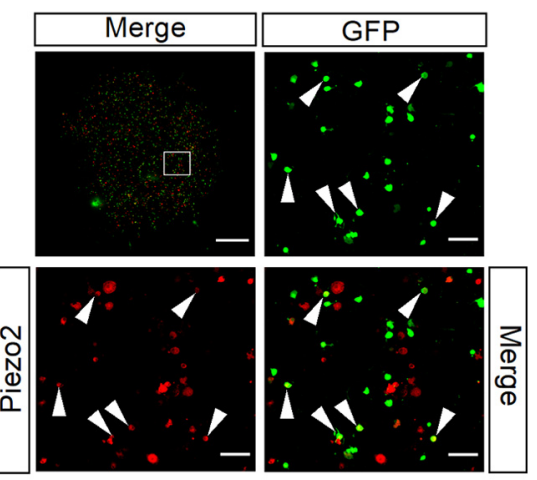

B

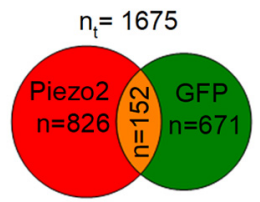

Figure 4. Piezo2 and TRPV1 are coexpressed in a small fraction of TG neurons. $\boldsymbol{A}$, Immunostaining of TG cultured neurons from TRPV1-EGFP mice with anti-GFP (green) and anti-Piezo2 (red). Top left, A composite image assembled from multiple high-resolution images of an entire coverslip. The boxed region is magnified in the right and bottom images. Arrowheads indicate examples of $\mathrm{GFP}^{+} / \mathrm{Piez02}^{+}$neurons. Scale bars: entire coverslip image, $1 \mathrm{~mm}$; magnified views, $100 \mu \mathrm{m}$. $\boldsymbol{B}$, Venn diagram showing the quantification of TG neurons that express Piezo2, TRPV1, and overlap between both populations [total number $\left(n_{t}\right)$ of neurons analyzed $=1675$.

percentage of corneal neurons responding to mechanical indentation, decreasing from $41.8 \%$ (115 of 275 ; Fig. $1 E$ ) in wild-type mice to $18.8 \%$ (19 of 101 neurons) in the Piezo $2^{c K O}$ mice (Fig. $6 A)$.

The distribution of inactivation time constants $\left(\tau_{\text {inact }}\right)$ was similar in wild-type and Piezo ${ }^{c K O}$ neurons (Fig. $6 B$ ). The majority of MS corneal neurons recorded in Piezo $2^{\text {cKO }}$ mice responded with RA currents $(73.7 \%, n=14 / 19)$, while indentation evoked SA currents in $21 \%(n=4$ of 19$)$ and IA currents in $5.3 \%(n=1$ of 19) of all corneal MS neurons. There were not significant differences in these proportions compared with wild-type mice (73.7\% vs $65.2 \%$ RA currents, $p=0.642 ; 5.26 \%$ vs $15.6 \%$ IA currents, $p=0.397 ; 21 \%$ vs $19.1 \%$, SA currents, $p=0.905$; $Z$-test). Likewise, the average values of membrane potential, rheobase, input resistance, peak current density, and cell capacitance of each type of MS neurons from Piezo $2^{c K O}$ mice were not different compared with wild-type mice. In contrast, the mechanical threshold decreased significantly in RA corneal neurons of Piezo $2^{\text {cKO }}$ mice (Table 2). Such modest differences in threshold may be explained by the variability within the few number of cells that responded to mechanical stimulation in the KO mice.

The proportion of RA MS neurons was reduced significantly in Piezo $2^{c K O}$ mice compared with wild-type mice (Fig. $6 \mathrm{~A} ; 13.9 \%$ vs $27.3 \%$ RA currents; $* * p=0.01, Z$-test). The proportions of IA and SA currents were also reduced (IA currents, $0.99 \%$ vs $6.55 \%$; SA currents, $3.96 \%$ vs $8 \%$ ), but differences did not reach statistical significance ( $p=0.056$ and $p=0.255$, respectively). A very low number of IA and SA MS neurons were recorded in Piezo2 $2^{\text {cKO }}$ mice. When grouped together, the proportion of IA/SA MS neurons was significantly reduced in Piezo $2^{c K O}$ mice (IA/SA currents, $14.6 \%$ vs $4.95 \%, p=0.018$; $Z$-test). However, average values of peak current density of RA and IA/SA MS neurons were similar when comparing Piezo $2^{\text {cKO }}(5.8 \pm 1.6 \mathrm{pA} / \mathrm{pF} ; n=14)$ to wildtype $(7.4 \pm 1.4 \mathrm{pA} / \mathrm{pF} ; n=75)$ RA currents $(p=0.906)$, and 
A

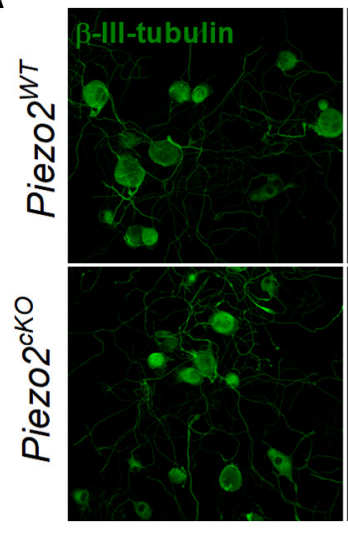

B

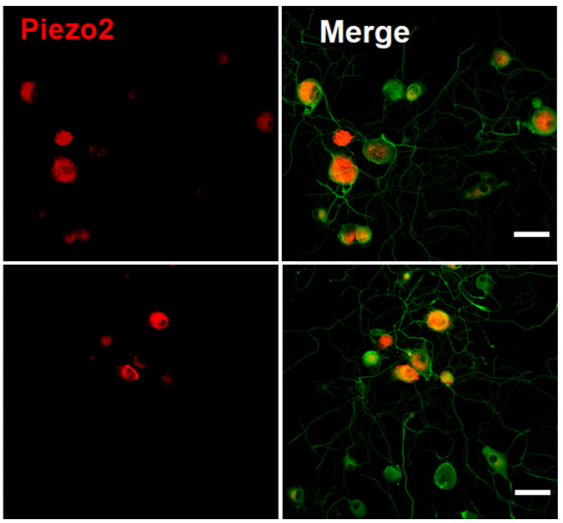

C

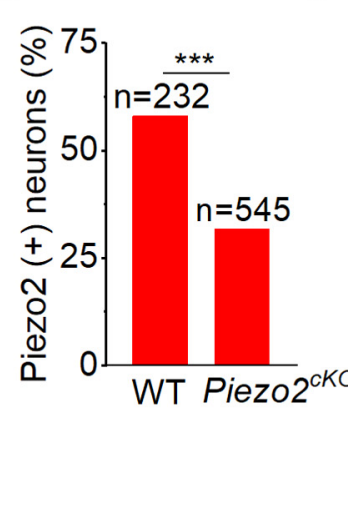

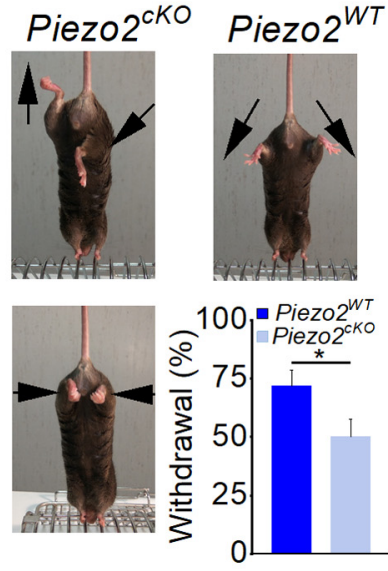

D
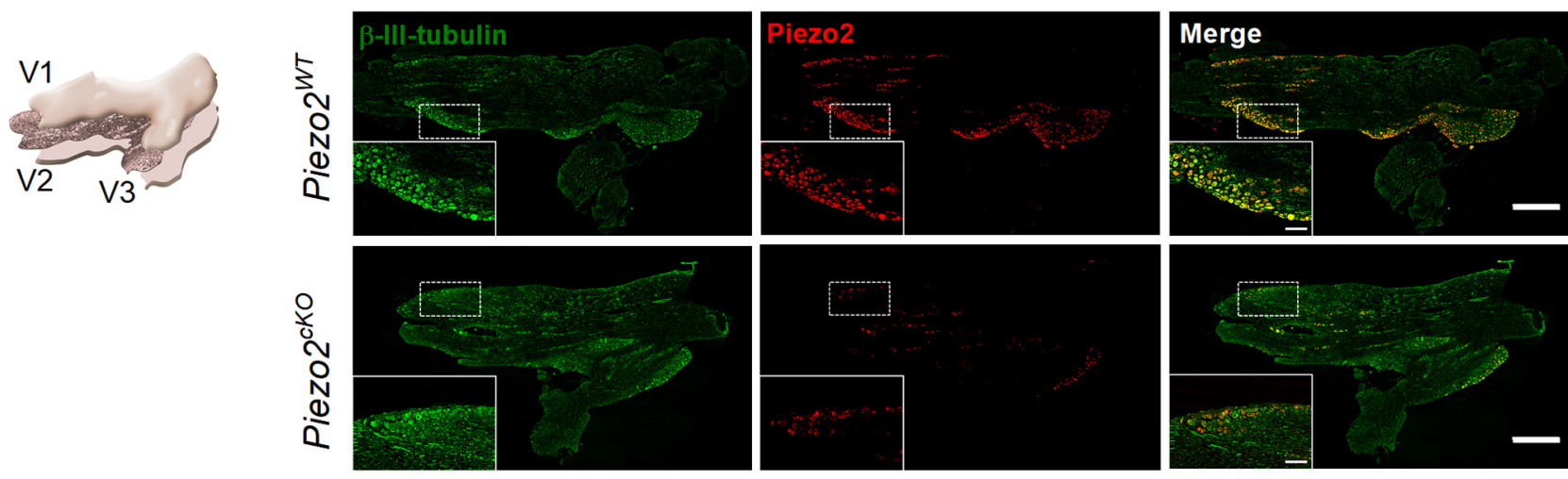

E
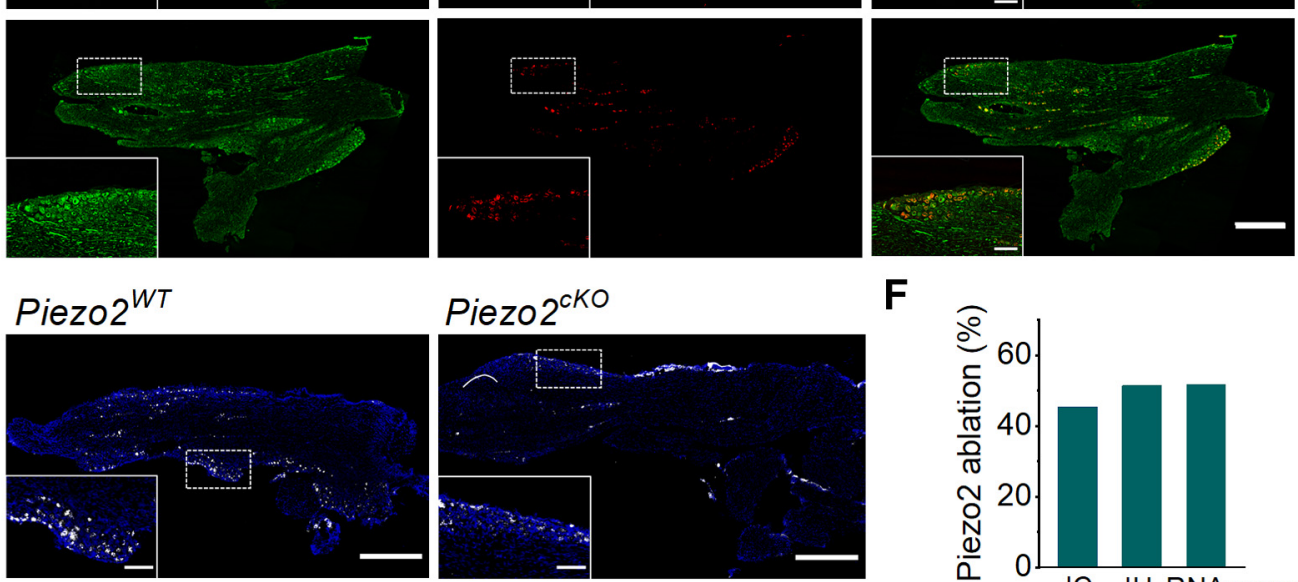

$\mathbf{F}$

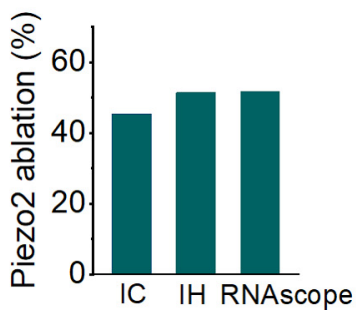

Figure 5. Histologic and functional characterization of Piezo2 ${ }^{\mathrm{cKO}}$ mice. $\boldsymbol{A}$, Images of cultured TG neurons immunostained for $\beta$-III-tubulin (green) and Piezo2 (red), and merged image from wild-type littermate and Piezo2 ${ }^{c K O}$ mice. Scale bars, $50 \mu \mathrm{m}$. B, Comparison of the percentage of Piezo2 ${ }^{+}$neurons in wild-type littermate $(n=2)$ and Piezo2 ${ }^{C K O}$ mice $\left(n=3 ; * * * p<0.001 ; Z\right.$-test). Five to seven coverslips were analyzed from each mouse. C, Representative images of leg posture in Piezo ${ }^{C K O}$ mice (left) when lifted by their tails, showing hindlimb retraction or opposite positioning. None of these postures was observed in their wild-types littermates (right); arrows indicate the orientation of the limbs. The bottom histogram shows the proportion of withdrawal responses to gentle sweep (repeated five times) with a cotton swab over the glabrous surface of the hindpaw in wild-type littermate $(n=9)$ and Piezo2 ${ }^{\text {cKO }}(n=9)$ mice. Error bars represent the SEM. $* p=0.025$, Student's $t$ test analysis. D, Schematic representation of the TG, illustrating the plane of section used for immunohistochemistry (left). The three peripheral nerves coming together, V1 (ophthalmic branch), V2 (maxillary branch), and V3 (mandibular branch), are indicated. Representative confocal images of sections of TG immunolabeled for $\beta$-III-tubulin (green) and Piezo2 (red), and the merged image in the right panels for wild-type littermates and for Piezo2 ${ }^{\text {KKO }}$. Piezo2 neurons only represent a fraction of $\beta$-III-tubulin ${ }^{+}$TG neurons. Scale bars, $500 \mu \mathrm{m}$. Insets show magnified views of the regions marked with the dotted squares. Scale bars, $100 \mu \mathrm{m}$. E, Representative confocal images of Piezo2 staining with the RNAscope probe in TG sections from wild-type littermate and Piezo2 ${ }^{\mathrm{cKO}}$ mice. White, Piezo2 transcripts; blue, DAPI. Scale bar, $500 \mu \mathrm{m}$. Insets show magnified views of the regions marked with the dotted squares. Scale bars, $100 \mu \mathrm{m}$. F, Histogram shows the percentage of the ablation of Piezo2 in Piezo2 ${ }^{\text {cKo }}$ mice using immunocytochemistry (IC), immunohistochemistry (IH), and RNAscope in situ hybridization techniques.

IA/SA currents $[5.9 \pm 3.1 \mathrm{pA} / \mathrm{pF}(n=5)$ vs $11.8 \pm 2.3 \mathrm{pA} / \mathrm{pF}$ $(n=40) ; p=0.213$; Student's $t$ test, Mann-Whitney rank-sum test; Fig. $6 C$ ], suggesting that Piezo2 accounts for the different types of MA currents.

Notably, none of the MA corneal neurons of Piezo $2^{c K O}$ mice in which CAP could be tested ( 8 of 19 ) responded positively to this compound (Fig. $6 \mathrm{C}$ ). This is not entirely surprising if we recall that the large majority (91.9\%) of MS neurons are capsaicin insensitive in wild-type mice.
Piezo2 is expressed in peripheral polymodal and pure mechanosensory axons of the mouse cornea

To further define the contribution of Piezo2 channels to the mechanical sensitivity of the different functional subclasses of corneal sensory neurons, we analyzed Piezo2 expression in their peripheral axons. A schematic diagram of corneal innervation is represented in Figure 7A, showing how the thick nerve trunks of the subepithelial plexus in the stroma give rise to ascending branches that penetrate through the basal lamina and split into 
A

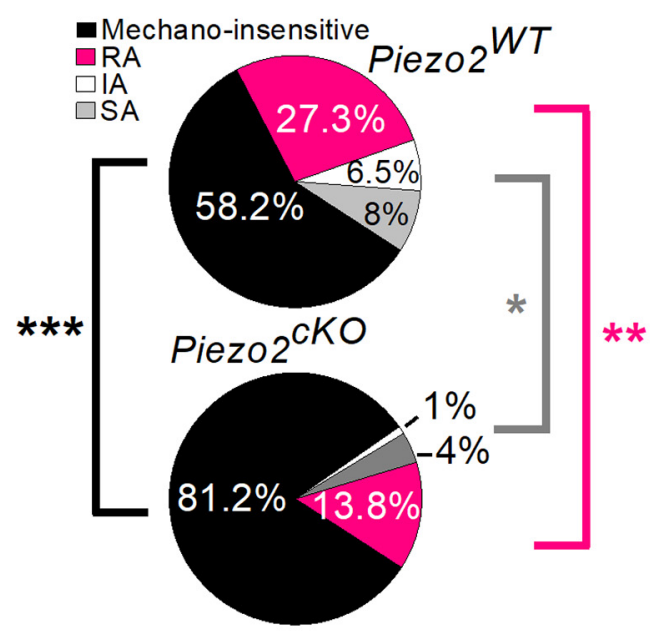

B

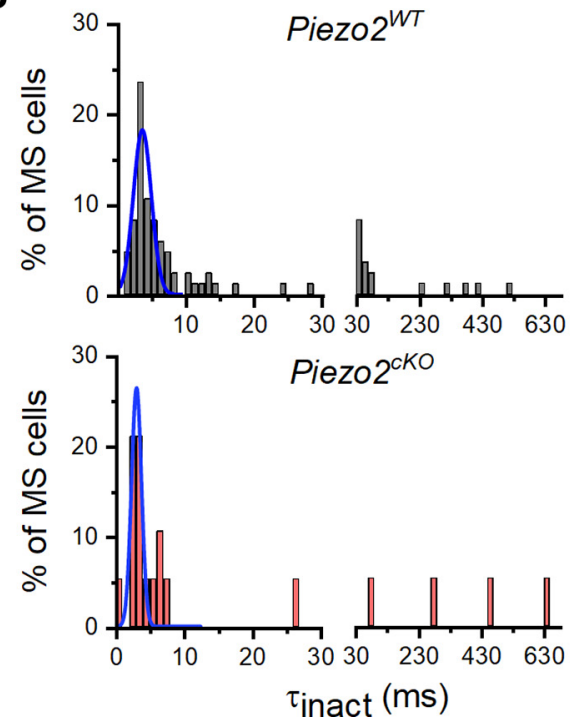

C

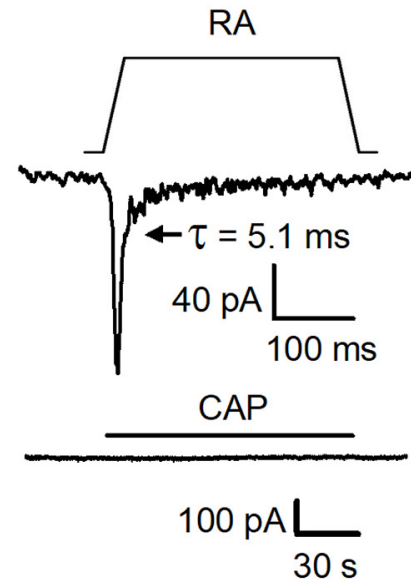

Figure 6. TG corneal mechanosensitive neurons are reduced in Piezo2 ${ }^{\mathrm{CKO}}$ mice. $A$, Pie plots show the proportion of mechano-insensitive and mechano-sensitive corneal trigeminal neurons and the distribution of the different types of mechanically activated currents, RA, IA, and SA, in wild-type (top, $n=275$ ) and Piezo2 ${ }^{\text {cKO }}$ (bottom, $n=101$ ) mice. Black asterisks indicate differences in the proportion of mechano-insensitive neurons. Pink and gray asterisks indicate differences between proportions of RA and IA/SA currents, respectively, for wild-type versus Piezo ${ }^{c K O}$ mice ( $* * * p<0.001, * * p=0.01, * p=0.018$; Z-test analysis). $\boldsymbol{B}$, Frequency distribution of inactivation time constants $\left(\tau_{\text {inact }}\right.$ ). Data collected from 85 TG neurons in wild-type and 19 in Piezo2 ${ }^{C K O}$ mice, voltage clamped at $-60 \mathrm{mV}$ and mechanically activated. Gaussian fits (blue traces) identified only one peak of inactivation time $\left(\tau ; 3.75 \pm 0.26 \mathrm{~ms}\right.$ for Piezo2 ${ }^{W T}$ mice and $3.05 \pm 0.13 \mathrm{~ms}$ for Piezo2 ${ }^{\mathrm{CKO}}$ mice). The bin width was $1 \mathrm{~ms}$ up to $30 \mathrm{~ms}$, and $20 \mathrm{~ms}$ from $30 \mathrm{~ms}$ onward. C, Example of a corneal neuron of Piezo ${ }^{c K O}$ mice that displayed RA MA currents and did not respond to $100 \mathrm{~nm}$ capsaicin (bottom; $V_{\text {hold }}=-60 \mathrm{mV}$ ). Mechanical stimulus $(11 \mu \mathrm{m})$ is indicated on top of the recording (top). Time constant of current inactivation is indicated in the panel.

thin, parallel nerve bundles of 7-20 fibers ("leashes") in the subbasal plexus (Alcalde et al., 2018). These thin nerve bundles, which run just below the corneal basal epithelium cell layer, give rise to ascending nerve terminal branches along their long trajectory that end at variable heights between the stratified corneal epithelium cells (Müller et al., 2003; Marfurt et al., 2010). To visualize the trajectories of nerves traveling from the corneal stroma to the epithelium, we performed triple immunolabeling in whole mounts of the cornea from C57BL/6J mice stained with antibodies for $\beta$-III-tubulin (red), TRPV1 (green), and Piezo2 (white) (Fig. $7 B$ ). In some experiments from TRPV1-GFP mice, we used an anti-GFP antibody to identify putative TRPV1 ${ }^{+}$endings. Analysis of confocal image stacks in flattened corneal wholemounts allowed us to follow the full trajectories of subepithelial bundles, individual sub-basal nerve axons, and intraepithelial terminals. Figure $7 B$ shows a representative example of a subepithelial nerve bundle in the stroma (Fig. $7 B$, arrowhead), the penetration points through the basal lamina of the ascending subepithelial nerve bundles (Fig. $7 B$, circles), and their branching into sub-basal axons. Subepithelial bundles and sub-basal axons labeled for TRPV1 were frequent, but none of them stained for Piezo2. Nonetheless, we observed coimmunostaining of Piezo2 and TRPV1 in the majority of penetration points (Fig. 7B, yellow circles). Only a few of these penetration points were labeled only for Piezo2 or TRPV1 (Fig. 7B, cyan circle, labeled for TRPV1 and negative for Piezo2).

In an attempt to improve visualization of Piezo2 in corneal nerve fibers, we used an alternative strategy, carrying out triple immunostaining in corneas from Piezo2-GFP-IRES-Cre (Piezo2 ${ }^{\text {GFP }}$ ) mice, which was previously shown to label Piezo2 in sensory neurons (Woo et al., 2014), colocalizing the GFP label (white) with immunostaining for $\beta$-III-tubulin (red) and TRPV1 (green) (Fig. $7 C$, $D, E$ ). We found subepithelial nerve bundles (Fig. $7 C$ ) and sub-basal nerve fibers (Fig. $7 D)$ positive for GFP and TRPV1 $(n=5$ corneas from 5 mice). We additionally identified a few epithelial terminals characterized as "simple" nerve terminals (Alamri et al., 2015) expressing Piezo 2 and TRPV1 with anti-GFP and anti-TRPV1 antibodies in whole-mount corneas of Piezo2 ${ }^{G F P}$ mice (Fig. 7E, yellow arrowhead). Other intraepithelial nerve terminals were positive only for TRPV1 (Fig. 7E, cyan arrowheads). Despite our efforts, the detection of Piezo2 in corneal nerves was irregular among samples, making it difficult to quantify the coexpression of Piezo2 and TRPV1. Thus, using TRPV1-GFP mice, we made a general estimation of the spatial distribution and the density of presumed Piezo $2^{+} / \mathrm{TRPV}_{1}{ }^{+}, \mathrm{Piezo}^{+} / \mathrm{TRPV} 1^{-}, \mathrm{Piezo}^{-} / \mathrm{TRPV} 1^{-}$and Piezo $2^{-} / \mathrm{TRPV}^{+}{ }^{+}$nerve bundles by counting the number of basal lamina penetration points of branches running into the different corneal epithelium layers that exhibited positive immunostaining to three markers: $\beta$-III-tubulin, GFP, and Piezo 2 (Fig. 7F; four corneas from three mice). We found that $86.5 \%$ of the basal lamina nerve bundle penetration points showed TRPV1 immunofluorescence; $\sim 40 \%$ of them also expressed Piezo2. Penetration points marked only for Piezo 2 were very rare (Fig. $7 F$, pie plot). Quantification of penetration points positive for Piezo 2 in the Piezo $2^{c K O}$ mice evidence a modest but significantly reduced proportion, from $41.5 \%$ to $32.7 \%$ (three corneas from three mice; Fig. $7 G$ ).

Altogether, the results with immunocytochemical staining confirm the presence of Piezo2 in many of the peripheral axons of TG neurons innervating the cornea, although very few ascending intraepithelial nerve terminal branches expressing Piezo2 were identified, and the significant reduction of Piezo2 expression in corneal nerves of the Piezo $2^{c K O}$ mice.

Piezo2 contributes to mechanical sensitivity in corneal pure mechanoreceptor and polymodal nociceptor sensory nerve terminals

To test directly the hypothesis that Piezo2 participates in the peripheral transduction of mechanical forces by the different 

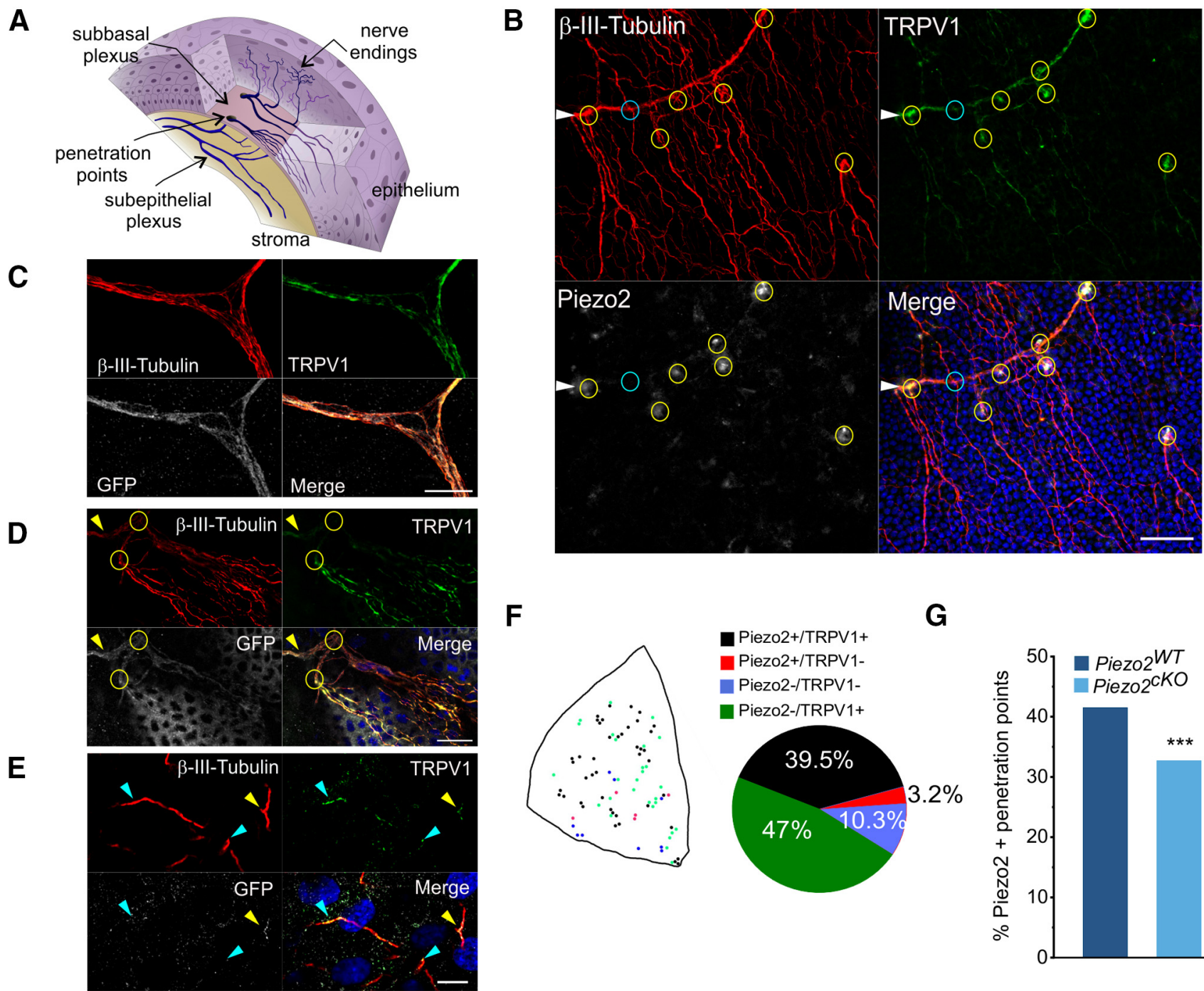

$\mathbf{F}$

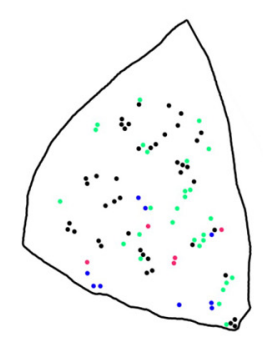

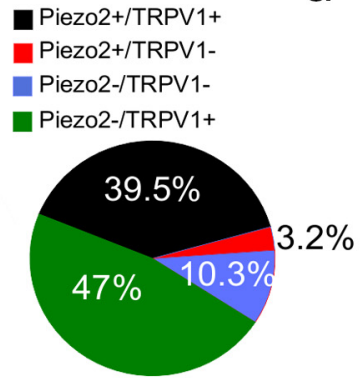

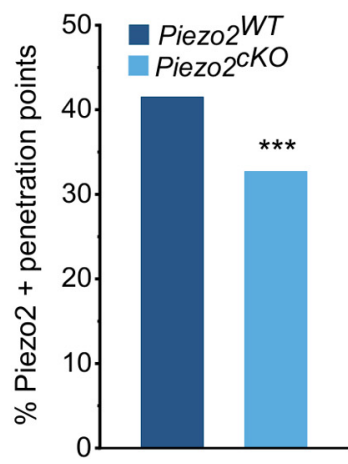

Figure 7. Piezo2 is detected in mouse corneal nerve terminals. $\boldsymbol{A}$, Sketch of the neuroanatomical structure of the cornea. The subepithelial nerves in the stroma traverse the basal lamina through penetration points and branch into sub-basal plexuses that give rise to ascending intraepithelial terminals. B, Z-stacked confocal images of a whole-mount cornea from a C57BL/6J mouse, showing a subepithelial bundle (arrowhead), points where subepithelial nerves penetrate the basal lamina (circles) and thinner sub-basal nerves after penetrating through the basal lamina. Nerves were immunolabeled with anti- $\beta$-III-tubulin (red), nerve fibers immunopositive for TRPV1 display green fluorescence, and those immunopositive to the Piezo2 antibody appear stained in white. Yellow circles indicate the penetration points with nerve bundles positive for TRPV1 and Piezo2, and a cyan circle points to a penetration point positive only for TRPV1. Nuclei of the epithelial cells are stained with Hoechst 33342 stain (blue). Scale bar, $50 \mu \mathrm{m}$. $\mathbf{C}-\mathbf{E}$, Confocal images of whole-mount corneas from Piezo2-GFP-IRES-Cre mice immunolabeled with anti$\beta$-III-tubulin (red), anti-TRPV1 (green), and anti-GFP (white) antibodies. C, Subepithelial nerve bundle containing many individual axons in the stromal layer. Nerve bundles were positive for TRPV1 and Piezo2. Scale bar, $10 \mu \mathrm{m}$. D. Circles indicate points where a subepithelial nerve (arrowhead) penetrates the basal lamina and divides into sub-basal nerves. Scale bar, $25 \mu \mathrm{m}$. $\boldsymbol{E}$, Simple nerve ending in the corneal epithelium layer that coexpresses Piezo2 and TRPV1 (yellow arrowhead). Cyan arrowheads point to terminals positive for TRPV1, and negative for Piezo2. Nuclei of the epithelial cells are stained with Hoechst 33342 stain (blue). Scale bar, $10 \mu \mathrm{m} . \boldsymbol{F}$, Schematic representation of the penetration points of nerve bundles in a corneal quadrant; color code indicates the expression of Piezo2 and/or TRPV1. Proportion of penetration points expressing Piezo2 ${ }^{+} / \mathrm{TRPV}^{+}$, Piezo2 ${ }^{+} / \mathrm{TRPV1}^{-}$, Piezo2 $/ \mathrm{TRPV1}^{-}$, or Piezo2 ${ }^{-} / \mathrm{TRPV}^{+}{ }^{+}(n=1347$ from four corneas, divided into four quadrants) is represented in the pie chart. G, Proportion of penetration points positive for Piezo2 in wild-type and Piezo2 ${ }^{c K O}$ mice. $* * * p<0.001, Z$-test analysis.

functional classes of corneal sensory endings, we recorded NTI activity in functionally characterized single sensory endings of the cornea in Piezo $2^{c K O}$ mice and their wild-type littermates. Active terminals were identified by placing the recording electrode sequentially onto neighboring points of the corneal surface (González-González et al., 2017), searching for the presence of spontaneous activity and/or responsiveness to $100 \mu \mathrm{m}$ and/or $200 \mu \mathrm{m}$ mechanical indentations. The sensitivity of corneal terminals to heat (i.e., polymodal nociceptor) and cold (i.e., cold thermoreceptor) was subsequently explored. In wild-type littermates of Piezo $2^{c K O}$ mice, mechanical sensitivity to $100 \mu \mathrm{m}$ and/ or $200 \mu \mathrm{m}$ was observed in approximately one-fourth of the total recording attempts (36 nerve terminals in 157 corneal surface points tested; Fig. $8 A, B$ ). Terminals responding to a mechanical stimulus and to heating over $40^{\circ} \mathrm{C}$ were classified as polymodal nociceptors and were recorded with a probability of $7.6 \%$ (Fig. $8 C$ ). In a few cases (4 of 36) in which mechanically sensitive/ cold-insensitive corneal terminals were obtained, the recording was lost before heat application; thus, their functional subcategory within the group of mechanosensitive terminals could not be further identified. The probability of recording at a site that responded only to the mechanical stimulus, thus classified as pure mechano-nociceptor terminals, was low (3.2\%; Fig. 8C). Finally, the probability to record mechano-cold receptors (i.e., terminals responding to indentation plus cooling ramps down to $12^{\circ} \mathrm{C}$ was 9.6\%; González-González et al., 2017; Fig. 8C). In 

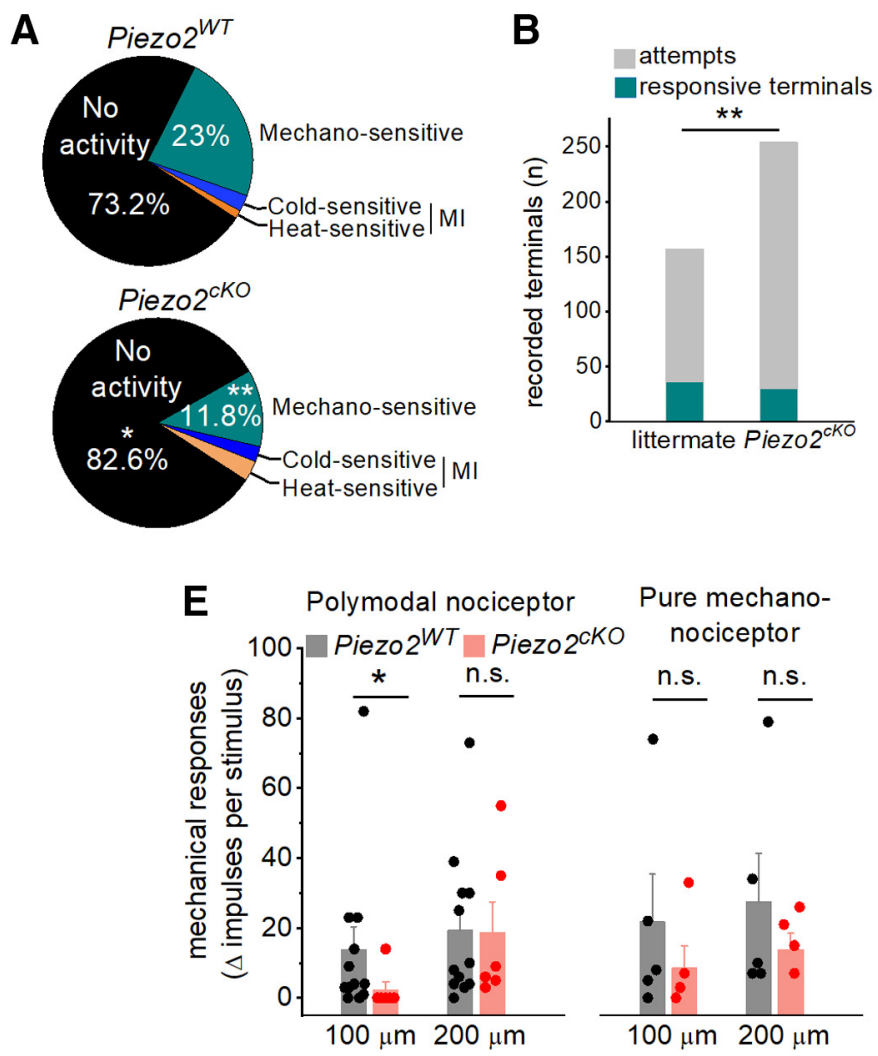
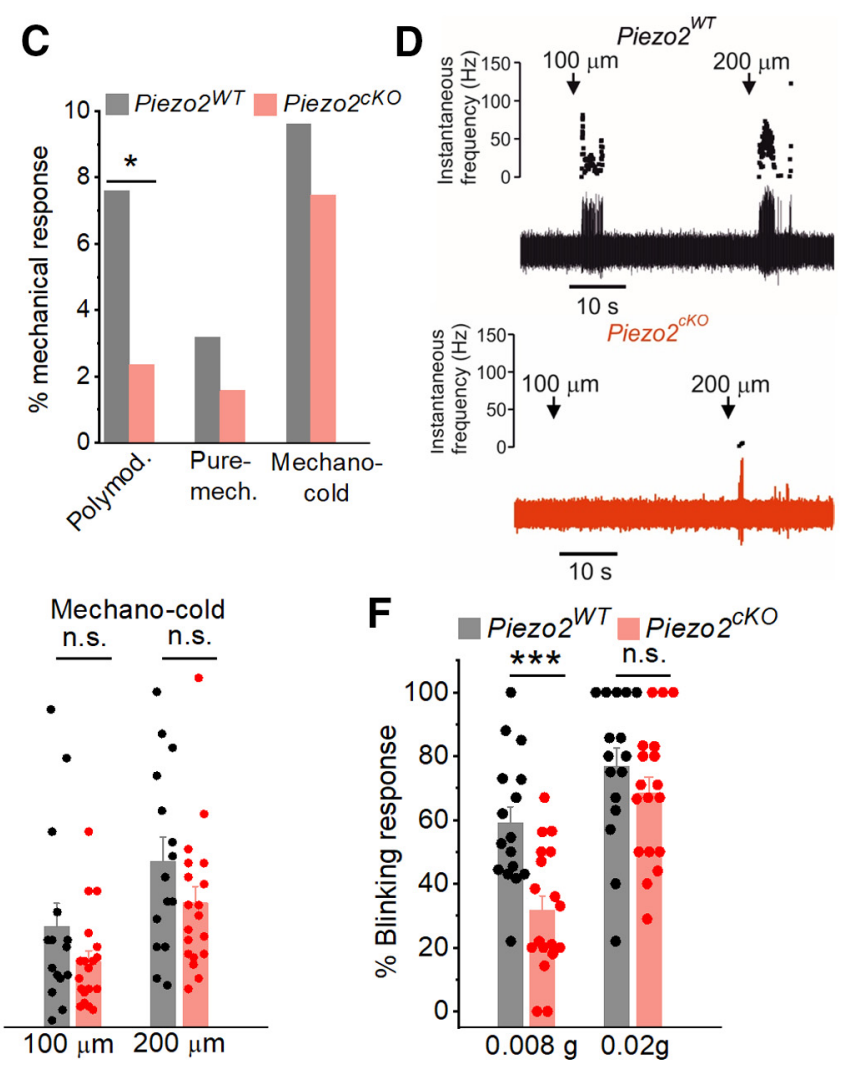

F

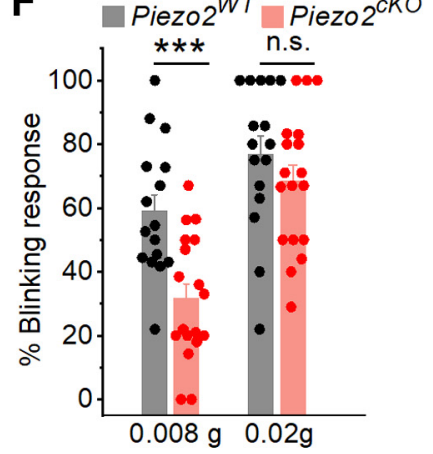

Figure 8. Piezo2 is involved in corneal nerve terminal mechanosensitivity. $\boldsymbol{A}$, Distribution of the different functional classes of corneal terminals recorded in wild-type littermates (15 eyes from 9 animals) and Piezo ${ }^{\text {cKO }}$ mice (20 eyes from 15 animals; $* * p=0.004$; Z-test). $\boldsymbol{B}$, Stacked bar plot shows significant differences in the successful attempts of recording a terminal from wild-type (157 corneal points) compared with Piezo2 ${ }^{c K O}$ (254 corneal points) mice. C, Proportion of corneal mechanosensitive terminals, identified as polymodal nociceptors, pure mechanoreceptors, and mechano-cold receptors from wild-type littermates (gray) and Piezo $2^{\text {cKO }}$ mice (light red; 5 pure-mechanoreceptors, 12 polymodal nociceptors, and 15 cold thermoreceptors in littermate mice; 4 pure mechanoreceptors, 6 polymodal nociceptors, and 19 cold thermoreceptors in Piezo ${ }^{\text {cKO }}$ mice; $* p<0.023 ;$ Z-test). D, Example of NTI activity in polymodal terminals from a wild-type littermate (top) and a Piezo2 ${ }^{c K O}$ mice (bottom) evoked by a $5 \mathrm{~s}$ forward displacement (100 and $\left.200 \mu \mathrm{m}\right)$ of the recording electrode. Arrows indicate the onset of the stimulus. The instantaneous frequency is represented at the top, and the original nerve impulse recording at the bottom. $\boldsymbol{E}$, Histograms showing the increment of NTI activity of the different functional classes of corneal receptors in response to 100 and $200 \mu \mathrm{m}$ displacement of the recording electrode in wild-type littermate and Piezo $2^{\text {ckO }}$ mice. Statistically significant differences were observed only in polymodal nociceptors in response to $100 \mu \mathrm{m}$ ( $* p=0.033$; Student's $t$ test, Mann-Whitney rank-sum test; n.S., not significant). $\boldsymbol{F}$, Proportion of blink responses to the application of von Frey filaments $(0.008$ and $0.02 \mathrm{~g})$ to the cornea in wild-type littermate $(n=16)$ and Piezo $2^{c K 0}(n=18)$ mice. $* * * p<0.001$ (Student's $t$ test). n.S., not significant. $\boldsymbol{E}$, $\boldsymbol{F}$, Bars represent the averaged response, and the scattered symbols show the individual values of terminal recordings $(\boldsymbol{E})$ or for each mice $(\boldsymbol{F})$.

addition, a small proportion of nerve terminals were insensitive to mechanical indentation and responded only to cold $(2.5 \%)$ or to heat (1.3\%; Fig. $8 A)$.

Compared with wild-type mice, in Piezo $2^{c K O}$ mice the probability of recording mechanically activated terminals decreased significantly (30 terminals in 254 tested points, 11.8\%; Figs. $8 A, B$; $* * p=0.004, Z$-test). In other words, to record the same number of mechanically sensitive terminals, a significantly higher number of attempts was required (Fig. $8 B$ ). This was due essentially to the lower presence of mechanosensory polymodal nociceptor $(2.4 \% ; * p=0.023)$ and of pure mechano-nociceptor terminals (1.6\%), while mechano-cold thermoreceptor terminals were less affected (7.9\%; Fig. 8C); only one terminal initially activated by indentation but not by cold was identified by the recording and lost before heat application. Mechano-insensitive nerve terminals responding only to cold $\left(12^{\circ} \mathrm{C} ; 2.4 \%\right)$ or heat (over $40^{\circ} \mathrm{C} ; 3.2 \%$ ) were also found in Piezo $2^{c K O}$ mice (Fig. $8 A$ ). These results evidence that Piezo2 ablation reduced, in a variable degree, the impulse activity evoked by moderate indentation in the different modalities of corneal sensory nerve terminals. As shown in Figure $8 C$, this reduction affected mainly the mechano-sensitive and heat-sensitive polymodal nociceptor terminals and pure mechanosensory-nociceptors terminals. The mechanical respon- siveness of cold thermoreceptors in Piezo $2^{c K O}$ mice remained essentially unaltered (Fig. 8C).

We further noticed that the response to force of the mechanosensitive terminals of Piezo $2^{c K O}$ mice maintaining mechanical responsiveness appeared subtly altered. The sensitivity to low-intensity mechanical stimulation, expressed as the increment of NTIs evoked by sequential 100 and $200 \mu \mathrm{m}$ indentation pulses compared with basal activity, tended to be lower in Piezo2 $2^{\text {cKO }}$ mice compared with wild-type littermates (Fig. $8 D, E$ ) and affected differently the functional subpopulations of corneal terminals (Fig. $8 E$ ). In Piezo $2^{c K O}$ mice $(n=6)$, only one of the six polymodal terminals responded to $100 \mu \mathrm{m}$ indentation (Fig. $8 E$ ); altogether, the number of NTIs fired by polymodal nociceptor terminals in response to $100 \mu \mathrm{m}$ indentations was significantly reduced compared with wild-type mice $(n=12$; mean, $13.8 \pm 6.6$ vs $2.3 \pm 2.3 ; * p=0.033$; Fig. $8 D$, example); no significant differences were observed in the number of NTI discharge evoked by $200 \mu \mathrm{m}$ indentation (mean, $19.3 \pm 6.2$ vs $18.8 \pm 8.7$; Fig. $8 E$ ). Pure mechano-nociceptors firing responses to 100 and $200 \mu \mathrm{m}$ in Piezo $2^{c K O}$ mice $(n=4)$ were substantially reduced $(21.8 \pm 13.6$ vs $10.8 \pm 7.6$ and $27.4 \pm 13.9$ vs $17.25 \pm 4.1$ NTIs, respectively), but not significantly different when compared with littermates $(n=5)$. 
Table 3. Duration of the nerve terminal impulses discharge

\begin{tabular}{lccc}
\hline Terminal type & Indentation & WT & Piezo2 $^{\text {cKO }}$ \\
\hline Polymodal nociceptor & $100 \mu \mathrm{m}$ & $1.89 \pm 0.5$ & 0.8 \\
& & $(n=9)$ & $(n=1)$ \\
& $200 \mu \mathrm{m}$ & $1.9 \pm 0.36$ & $1.55 \pm 0.25$ \\
& & $(n=11)$ & $(n=6)$ \\
Pure mechano-nociceptor & $100 \mu \mathrm{m}$ & $1.9 \pm 1.04$ & $1.3 \pm 0.32$ \\
& & $(n=4)$ & $(n=3)$ \\
& $200 \mu \mathrm{m}$ & $1.2 \pm 0.38$ & $1.7 \pm 0.66$ \\
& & $(n=5)$ & $(n=4)$ \\
Cold thermoreceptors & $100 \mu \mathrm{m}$ & $2.5 \pm 0.55$ & $3.6 \pm 0.41$ \\
& & $(n=12)$ & $(n=12)$ \\
& $200 \mu \mathrm{m}$ & $3.7 \pm 0.4$ & $3 \pm 0.28$ \\
& & $(n=15)$ & $(n=19)$ \\
\hline
\end{tabular}

Average time (in seconds) of NTIs during the $5 \mathrm{~s}$ indentation in the cornea. Data are presented as the mean \pm SE. Statistical comparison of NTls between wild-type and Piezo2 ${ }^{2 K O}$ mice was performed using the Student's $t$ test and Mann-Whitney rank-sum test.

In cold thermoreceptors, the responses to 100 and $200 \mu \mathrm{m}$ indentations were not significantly different in wild-type mice $(n=15)$ and Piezo $2^{c K O}$ mice $(n=19 ; 23.9 \pm 6.8$ vs $13.9 \pm 3.1$ and $42.6 \pm 6.8$ vs $30.6 \pm 4.5$ NTIs, respectively; Fig. $8 E$ ).

Mechanically activated corneal terminals generated a short burst of NTIs at the onset of the $5 \mathrm{~s}$ indentation. The duration of the NTI discharges was $<5 \mathrm{~s}$ in all types of corneal terminals. This pattern corresponds to a fast adaptation that inactivates before the termination of mechanical stimulation. No significant differences were observed in the duration of the NTIs to 100 and $200 \mu \mathrm{M}$ indentation in wild-type mice compared with Piezo ${ }^{c K O}$ mice in the three types of corneal terminals (Table 3 ).

In summary, the number of responsive terminals and activity, measured as terminal impulse firing, was reduced in Piezo $2^{c K O}$ mice at the lowest mechanical force used. These results suggest that Piezo2 contributes variably to nerve impulse responses to mechanical forces in corneal nerve endings of different nociceptive submodalities.

\section{Piezo $2^{\text {cKO }}$ mice show impaired reflex blinking to low- threshold mechanical stimuli}

Mechanosensitivity plays an essential role in triggering the protective eye-blinking response (VanderWerf et al., 2003). We quantified the contribution of Piezo2 channels to eye blinking evoked by light mechanical stimulation in unanesthetized animals, counting the number of blinks after unilateral application of von Frey hairs of 0.008 and $0.02 \mathrm{~g}$ to the corneas of Piezo ${ }^{c K O}$ mice and their wild-type littermates. The average proportion of blinks evoked with the finest von Frey hair (0.008 g) was significantly reduced in Piezo $2^{c K O}$ mice (wild-type mice, $59 \pm 5.2$; vs Piezo $2^{\text {cKO }}$ mice, $31.6 \pm 4.6 ; p<0.001$; Fig. $8 F$ ). In contrast, no significant differences with wild-type littermate mice were observed when higher forces ( $0.02 \mathrm{~g}$ hairs; wild-type mice, $77 \pm 5.7$; vs Piezo $2^{c K O}$ mice, $68.4 \pm 5.0 ; p=0.273$; Fig. $8 F$ ) were applied.

\section{Discussion}

Mechanical pain is a vital protective response to minimize corneal injury. Here, we characterized, for the first time, the mechanically activated currents present in a well identified functional population of TG corneal sensory neurons in mammals. We show that a large fraction of these neurons, belonging to pure mechanosensory and polymodal nociceptor corneal neuron classes, exhibit MA currents and express Piezo2 channels. Experiments in Piezo $2^{c K O}$ mice strongly suggest an involvement of Piezo2 channels in the transduction of noxious mechanical forces by both types of mechanosensitive neurons. Indeed, a significant reduction in the number of nociceptor neurons exhibiting MA currents was observed in Piezo ${ }^{c K O}$ mice. Unfortunately, the efficiency of genetic deletion of Piezo2 in the conditional mouse line that we used is not complete, as previously demonstrated by others (Zhang et al., 2019) and confirmed by our results. Still, we were able to successfully eliminate Piezo2 in $\sim 50 \%$ of TG neurons, and this reduction was accompanied by an equivalent reduction $(\sim 55 \%)$ of the TG corneal neurons exhibiting MA currents, indirectly supporting the conclusion that the majority of MA currents in corneal TG neurons are linked to the expression of Piezo2.

The presence of Piezo2-dependent mechanosensitivity in RA IA and SA neurons indicates that Piezo2 channels contribute to all these current types in nociceptive corneal neurons. This is in full agreement with recent observations in cell bodies of mechanosensitive DRG neurons, including nociceptors, where all classes of currents are variably affected (Szczot et al., 2018; Murthy et al., 2018b). Differences in the kinetics of Piezo2-mediated currents in individual MS neurons may be partially explained by several factors, such as interaction of the channel with other proteins or membrane lipids or by the existence of several splice isoforms of Piezo2 in mouse sensory ganglion neurons that tunes the inactivation of Piezo2 (Hong et al., 2016; Szczot et al., 2017; Anderson et al., 2018). Future studies on structure-function relationships may help reveal Piezo2 kinetic mechanisms at the single-cell level.

In our view, the observed reduction in the proportion of IA/ SA neurons in the Piezo ${ }^{c K O}$ mice suggests a direct involvement of Piezo2 in these currents, but we cannot exclude that Piezo2 deletion might have effects on gene expression, leading to an upregulation/downregulation of other proteins in sensory neurons, as occurs with other channels (Minett et al., 2015). The fraction of MA currents still recorded in corneal neurons of Piezo2 $2^{\text {cKO }}$ mice are most likely attributable to the residual expression of the channel in some neurons of these mice. Nevertheless, MA currents were recorded in a few corneal neurons lacking Piezo2, suggesting that another, still unidentified, MA channel contributes to their mechanosensitivity (Zappia et al., 2017; Murthy et al., 2018a).

About two-thirds of the corneal terminals of cold thermoreceptor neurons, another main functional sensory receptor neuron type innervating the cornea, also responded to mechanical stimulation, thus defining them as mechano-cold terminals. Nonetheless, our results in identified corneal cold thermoreceptor neurons suggest that their mechanical responsiveness is not mediated by Piezo2 channels because no MA currents were evoked in cultured cold thermoreceptor neurons expressing TRPM8, the defining molecular marker for this subpopulation of corneal sensory neurons. This functional result agrees with the lack of Piezo2 immunostaining in TRPM8-expressing corneal afferent neurons reported by Bron et al. (2014). Therefore, the mechanism mediating mechanosensitivity in cold corneal endings remains an open question, as occurs with our limited understanding of mechanosensory transduction in cutaneous cold receptors (Winter et al., 2017). It is worth noting that corneal endings respond to hyperosmotic stimuli, a different type of mechanical perturbation, and that this response is mediated by TRPM8 (Quallo et al., 2015).

Altogether, our work shows that genetic ablation of Piezo2 reduced nerve terminal impulse activity of pure mechanosensory and polymodal nociceptor neurons and decreased mechanically evoked protective blink reflexes, thus suggesting that Piezo2 
participates in the detection of low-intensity but already harmful mechanical stimuli to the eye.

The conclusion that Piezo2 is expressed by corneal neurons, which have been functionally defined as nociceptive neurons evoking pain (Belmonte et al., 1991), is additionally confirmed by the immunocytochemical demonstration of Piezo2 staining in peripheral corneal axons. Of note, Piezo2 immunoreactivity was mainly accumulated at the penetration points of ascending stromal nerve bundles into the basal lamina, likely reflecting the presence of axons that contain Piezo2. Very few ascending nerve branches expressing only Piezo2 were found. This may be because of a low proportion of pure mechano-nociceptors ( $\sim 10 \%$ in mouse cornea; González-González et al., 2017) or that nerve terminals expressing Piezo2 only (i.e., pure mechano-nociceptors) terminate at deeper epithelium levels, near the basal lamina (Alamri et al., 2018), where we located most Piezo2-immunoreactive fibers. Nerve endings expressing TRPV1 were more frequently identified, suggesting their polymodal character but a precise estimation of the number of polymodal nociceptor neurons innervating the cornea coexpressing Piezo2 appears challenging because of the very few nerve endings that express Piezo2.

In line with our findings in the soma, genetic Piezo2 deletion produced a marked reduction in the mechanosensitivity of peripheral corneal nerve terminals. It is noteworthy, in Piezo $2^{c K O}$ mice corneas, that nerve terminals showing mechanical sensitivity, in particular polymodal nociceptors, fired a lower number of NTIs when subjected to a stimulus of $100 \mu \mathrm{m}$ indentation when compared with those of wild-type mice. A possible explanation for this observation is that Piezo2 is responsible for the initial response of the cornea to a low-intensity mechanical stimulation. It is tempting to speculate that the expression of Piezo 2 confers to corneal mechanosensory nociceptor terminals the transduction sensitivity required to reach firing threshold under moderate but potentially injurious mechanical forces. With stronger, overtly noxious indentations $(200 \mu \mathrm{m})$, the differences in response between wild-type and Piezo $2^{c K O}$ mice disappeared. This difference may suggest the expression of additional mechanosensitive channels at these terminals (Murthy et al., 2018a) or of other membrane-associated molecules involved in mechanotransduction (Janmey and Kinnunen, 2006; Nezu et al., 2010).

The direct relationship between mechanical stimulation of the cornea and protective reflex lid closure is firmly established (VanderWerf et al., 2003; Henriquez and Evinger, 2007). Piezo $2^{c K O}$ mice show reduced blinking responses to light corneal mechanical stimulation, similar to what happens in the skin of Piezo2 ${ }^{c K O}$ mice (Murthy et al., 2018b), further supporting the functional relevance of this ion channel as a critical first line in the building of protective/defensive behaviors.

Peripheral sensory neurons are canonically defined by their preferential transducing capacities for a given form of energy and by the perceptual quality of the sensations evoked by their sensory input to the brain, which determines the final cognitive and affective characteristics of the perceptual experience. For corneal stimulation in humans and experimental animals, perception appears to be always unpleasant or overtly painful depending on the recruitment level of peripheral receptor terminals (Acosta et al., 2001; Moulton et al., 2012). Indeed, mechanonociceptor and polymodal nociceptor corneal neurons project centrally into the trigeminal subnucleus caudalis-cervical cord $(\mathrm{Vc} / \mathrm{Cl})$ junction region of the lower brainstem, the secondorder neural station of the eye surface pain pathways (Saito et al., 2017).
Our demonstration that Piezo2, a detector of mild forces, is also expressed by neurons belonging to a well defined population of pain-signaling peripheral corneal nociceptor neurons speaks against a direct correspondence between this mechanotransducer molecule and the sensory percept evoked by its activation. The innocuous forces required to stimulate LTMR tactile terminals in the keratinized skin are already injurious when applied to the unprotected corneal epithelium cells. Touch sensations are felt with air streams directed toward the eye, but they are attributable to immediate stimulation of the more sensitive, myelinated low-threshold mechanoreceptors of the eyelids, eyelashes, and exposed conjunctiva (Munger and Halata, 1984).

The cornea is highly vulnerable to injury by a variety of external mechanical forces with serious consequences on vision and health. Hence, the expression of Piezo2, a highly sensitive mechanotransducing molecule in corneal endings of TG neurons, can be considered an advantageous evolutionary adaptation in the innervation of this organ for early detection of potentially injurious mechanical forces. Nonetheless, it is worth noting that in transgenic mouse lines where lanceolate $\mathrm{A} \delta$-LTMRs and $\mathrm{A} \beta$ RA-LTMR nerve terminals of the skin are fluorescent (TrkB: TauGFP mice; Split:cre mice; Npy2r:tdTomato mice), corneal nerves do not appear to be labeled (Bouheraoua et al., 2019), suggesting that $\mathrm{Piezo}^{+}$neurons giving rise to cutaneous lowthreshold mechanoreceptors and those directed to the cornea mediating pain have different genetic signatures.

In summary, our findings reveal the key contribution of Piezo2 channels to the early activation of corneal nociceptor neurons, which has significant relevance for several ocular disorders. In the eye, rapid detection of low-intensity mechanical stimuli plays a particularly important protective role for the early prevention of corneal epithelium damage by foreign bodies or other external mechanical trauma. Moreover, it has been recently suggested that in dry eye disease, sliding of the eyelid over a corneal surface with reduced moistness causes mechanical stress, which damages epithelial cells, exciting corneal surface nociceptors, thereby aggravating pain and altered vision symptoms typical of this pathology (van Setten, 2020). Topical pharmacological modulation of Piezo 2 channels in corneal mechano-nociceptive nerve terminals appears as a potential therapeutic strategy to selectively attenuate the enhanced activity of sensitized corneal mechanonociceptor neurons underlying discomfort and pain in dry eye and other ocular surface pathologies.

\section{References}

Acosta MC, Belmonte C, Gallar J (2001) Sensory experiences in humans and single-unit activity in cats evoked by polymodal stimulation of the cornea. J Physiol 534:511-525.

Alamri A, Bron R, Brock JA, Ivanusic JJ (2015) Transient receptor potential cation channel subfamily $\mathrm{V}$ member 1 expressing corneal sensory neurons can be subdivided into at least three subpopulations. Front Neuroanat 9:71.

Alamri AS, Wood RJ, Ivanusic JJ, Brock JA (2018) The neurochemistry and morphology of functionally identified corneal polymodal nociceptors and cold thermoreceptors. PLoS One 13:e0195108.

Alcalde I, Iñigo-Portugues A, Gonzalez-Gonzalez O, Almaraz L, Artime E, Morenilla-Palao C, Gallar J, Viana F, Merayo-Lloves J, Belmonte C (2018) Morphological and functional changes in TRPM8-expressing corneal cold thermoreceptor neurons during aging and their impact on tearing in mice. J Comp Neurol 526:1859-1874.

Anderson EO, Schneider ER, Matson JD, Gracheva EO, Bagriantsev SN (2018) TMEM150C/Tentonin3 is a regulator of mechano-gated ion channels. Cell Rep 23:701-708

Belmonte C, Giraldez F (1981) Responses of cat corneal sensory receptors to mechanical and thermal stimulation. J Physiol 321:355-368. 
Belmonte C, Gallar J, Pozo MA, Rebollo I (1991) Excitation by irritant chemical substances of sensory afferent units in the cat's cornea. J Physiol 437:709-725.

Belmonte C, Garcia-Hirschfeld J, Gallar J (1997) Neurobiology of ocular pain. Progr Retin Eye Res 16:117-156.

Belmonte C, Acosta MC, Schmelz M, Gallar J (1999) Measurement of corneal sensitivity to mechanical and chemical stimulation with a $\mathrm{CO} 2$ esthesiometer. Invest Ophthalmol Vis Sci 40:513-519.

Belmonte C, Nichols JJ, Cox SM, Brock JA, Begley CG, Bereiter DA, Dartt DA, Galor A, Hamrah P, Ivanusic JJ, Jacobs DS, McNamara NA, Rosenblatt MI, Stapleton F, Wolffsohn JS (2017) TFOS DEWS II pain and sensation report. Ocul Surf 15:404-437.

Beuerman RW, Tanelian DL (1979) Corneal pain evoked by thermal stimulation. Pain 7:1-14.

Bouheraoua N, Fouquet S, Marcos-Almaraz MT, Karagogeos D, Laroche L, Chédotal A (2019) Genetic analysis of the organization, development, and plasticity of corneal innervation in mice. J Neurosci 39:1150-1168.

Bron R, Wood RJ, Brock JA, Ivanusic JJ (2014) Piezo2 expression in corneal afferent neurons. J Comp Neurol 522:2967-2979.

Cabanes C, López de Armentia M, Viana F, Belmonte C (2002) Postnatal changes in membrane properties of mice trigeminal ganglion neurons. J Neurophysiol 87:2398-2407.

Caterina MJ, Schumacher MA, Tominaga M, Rosen TA, Levine JD, Julius D (1997) The capsaicin receptor: a heat-activated ion channel in the pain pathway. Nature 389:816-824.

Chen X, Belmonte C, Rang HP (1997) Capsaicin and carbon dioxide act by distinct mechanisms on sensory nerve terminals in the cat cornea. Pain 70:23-29.

Chesler AT, Szczot M, Bharucha-Goebel D, Čeko M, Donkervoort S, Laubacher C, Hayes LH, Alter K, Zampieri C, Stanley C, Innes AM, Mah JK, Grosmann CM, Bradley N, Nguyen D, Foley AR, Le Pichon CE, Bönnemann CG (2016) The role of PIEZO2 in human mechanosensation. N Engl J Med 375:1355-1364.

Coste B, Mathur J, Schmidt M, Earley TJ, Ranade S, Petrus MJ, Dubin AE, Patapoutian A (2010) Piezo1 and Piezo2 are essential components of distinct mechanically activated cation channels. Science 330:55-60.

Drew LJ, Wood JN, Cesare P (2002) Distinct mechanosensitive properties of capsaicin-sensitive and -insensitive sensory neurons. J Neurosci 22: RC228.

Florez-Paz D, Bali KK, Kuner R, Gomis A (2016) A critical role for Piezo2 channels in the mechanotransduction of mouse proprioceptive neurons. Sci Rep 6:25923.

Gallar J, Pozo MA, Tuckett RP, Belmonte C (1993) Response of sensory units with unmyelinated fibres to mechanical, thermal and chemical stimulation of the cat's cornea. J Physiol 468:609-622.

Garrison SR, Dietrich A, Stucky CL (2012) TRPC1 contributes to light-touch sensation and mechanical responses in low-threshold cutaneous sensory neurons. J Neurophysiol 107:913-922.

González-González O, Bech F, Gallar J, Merayo-Lloves J, Belmonte C (2017) Functional properties of sensory nerve terminals of the mouse cornea. Invest Ophthalmol Vis Sci 58:404-415.

Hao J, Delmas P (2010) Multiple desensitization mechanisms of mechanotransducer channels shape firing of mechanosensory neurons. J Neurosci 30:13384-13395.

Henriquez VM, Evinger C (2007) The three-neuron corneal reflex circuit and modulation of second-order corneal responsive neurons. Exp Brain Res 179:691-702.

Hong GS, Lee B, Wee J, Chun H, Kim H, Jung J, Cha JY, Riew TR, Kim GH, Kim IB, Oh U (2016) Tentonin 3/TMEM150c confers distinct mechanosensitive currents in dorsal-root ganglion neurons with proprioceptive function. Neuron 91:107-118.

Hu J, Lewin GR (2006) Mechanosensitive currents in the neurites of cultured mouse sensory neurones. J Physiol 577:815-828.

Janmey PA, Kinnunen PK (2006) Biophysical properties of lipids and dynamic membranes. Trends Cell Biol 16:538-546.

Marfurt CF, Cox J, Deek S, Dvorscak L (2010) Anatomy of the human corneal innervation. Exp Eye Res 90:478-492.

Minett MS, Pereira V, Sikandar S, Matsuyama A, Lolignier S, Kanellopoulos AH, Mancini F, Iannetti GD, Bogdanov YD, Santana-Varela S, Millet Q, Baskozos G, MacAllister R, Cox JJ, Zhao J, Wood JN (2015) Endogenous opioids contribute to insensitivity to pain in humans and mice lacking sodium channel Nav1.7. Nat Commun 6:8967.
Morenilla-Palao C, Luis E, Fernández-Peña C, Quintero E, Weaver JL, Bayliss DA, Viana F (2014) Ion channel profile of TRPM8 cold receptors reveals a role of TASK-3 potassium channels in thermosensation. Cell Rep 8:1571-1582.

Moulton EA, Becerra L, Rosenthal P, Borsook D (2012) An approach to localizing corneal pain representation in human primary somatosensory cortex. PLoS One 7:e44643.

Müller LJ, Marfurt CF, Kruse F, Tervo TM (2003) Corneal nerves: structure, contents and function. Exp Eye Res 76:521-542.

Munger BL, Halata Z (1984) The sensorineural apparatus of the human eyelid. Am J Anat 170:181-204.

Murthy SE, Dubin AE, Whitwam T, Jojoa-Cruz S, Cahalan SM, Mousavi SAR, Ward AB, Patapoutian A (2018a) OSCA/TMEM63 are an evolutionarily conserved family of mechanically activated ion channels. Elife 7: e41844.

Murthy SE, Loud MC, Daou I, Marshall KL, Schwaller F, Kühnemund J, Francisco AG, Keenan WT, Dubin AE, Lewin GR, Patapoutian A (2018b) The mechanosensitive ion channel Piezo2 mediates sensitivity to mechanical pain in mice. Sci Transl Med 10:eaat9897.

Neher E (1992) Correction for liquid junction potentials in patch clamp experiments. Methods Enzymol 207:31.

Nencini S, Ivanusik J (2017) Mechanically sensitive A $\delta$ nociceptors that innervate bone marrow respond to changes in intra-osseous pressure. J Physiol 595:4399-4415.

Nezu A, Tanimura A, Morita T, Tojyo Y (2010) Visualization of Ins(1,4,5)P3 dynamics in living cells: two distinct pathways for Ins( $(1,4,5) \mathrm{P} 3$ generation following mechanical stimulation of HSY-EA1 cells. J Cell Sci 123:22922298.

Nguyen MQ, Wu Y, Bonilla LS, von Buchholtz LJ, Ryba NJP (2017) Diversity amongst trigeminal neurons revealed by high throughput single cell sequencing. PLoS One 12:e0185543.

Prato V, Taberner FJ, Hockley JRF, Callejo G, Arcourt A, Tazir B, Hammer L, Schad P, Heppenstall PA, Smith ES, Lechner SG (2017) Functional and molecular characterization of mechanoinsensitive "silent" nociceptors. Cell Rep 21:3102-3115.

Quallo T, Vastani N, Horridge E, Gentry C, Parra A, Moss S, Viana F, Belmonte C, Andersson DA, Bevan S (2015) TRPM8 is a neuronal osmosensor that regulates eye blinking in mice. Nature Commun 6:7150.

Ranade SS, Woo SH, Dubin AE, Moshourab RA, Wetzel C, Petrus M, Mathur J, Bégay V, Coste B, Mainquist J, Wilson AJ, Francisco AG, Reddy K, Qiu Z, Wood JN, Lewin GR, Patapoutian A (2014) Piezo2 is the major transducer of mechanical forces for touch sensation in mice. Nature 516:121-125.

Saito H, Katagiri A, Okada S, Mikuzuki L, Kubo A, Suzuki T, Ohara K, Lee J, Gionhaku N, Iinuma T, Bereiter DA, Iwata K (2017) Ascending projections of nociceptive neurons from trigeminal subnucleus caudalis: a population approach. Exp Neurol 293:124-136.

Schneider ER, Mastrotto M, Laursen WJ, Schulz VP, Goodman JB, Funk OH, Gallagher PG, Gracheva EO, Bagriantsev SN (2014) Neuronal mechanism for acute mechanosensitivity in tactile-foraging waterfowl. Proc Natl Acad Sci U S A 111:14941-14946.

Schneider ER, Anderson EO, Mastrotto M, Matson JD, Schulz VP, Gallagher PG, LaMotte RH, Gracheva EO, Bagriantsev SN (2017) Molecular basis of tactile specialization in the duck bill. Proc Natl Acad Sci 114:13036-13041.

Szczot M, Pogorzala LA, Solinski HJ, Young L, Yee P, Le Pichon CE, Chesler AT, Hoon MA (2017) Cell-type-specific splicing of Piezo2 regulates mechanotransduction. Cell Rep 21:2760-2771.

Szczot M, Liljencrantz J, Ghitani N, Barik A, Lam R, Thompson JH, Bharucha-Goebel D, Saade D, Necaise A, Donkervoort S, Foley AR, Gordon T, Case L, Bushnell MC, Bonnemann CG, Chesler AT (2018) PIEZO2 mediates injury-induced tactile pain in mice and humans. Sci Transl Med 10:eaaat9892.

Tominaga M, Caterina MJ, Malmberg AB, Rosen TA, Gilbert H, Skinner K, Raumann BE, Basbaum AI, Julius D (1998) The cloned capsaicin receptor integrates multiple pain-producing stimuli. Neuron 21:531-543.

VanderWerf F, Brassinga P, Reits D, Aramideh M, Ongerboer de Visser B (2003) Eyelid movements: behavioral studies of blinking in humans under different stimulus conditions. J Neurophysiol 89:2784-2796.

Vandewauw I, De Clercq K, Mulier M, Held K, Pinto S, Van Ranst N, Segal A, Voet T, Vennekens R, Zimmermann K, Vriens J, Voets T (2018) A TRP channel trio mediates acute noxious heat sensing. Nature 555:662666. 
van Setten G-B (2020) Impact of attrition, intercellular shear in dry eye disease: when cells are challenged and neurons are triggered. Int J Mol Sci 21:4333.

Viana F, de la Peña E, Pecson B, Schmidt RF, Belmonte C (2001) Swellingactivated calcium signalling in cultured mouse primary sensory neurons. Eur J Neurosci 13:722-734.

Weddell G, Zander E (1950) A critical evaluation of methods used to demonstrate tissue neural elements, illustrated by reference to the cornea. J Anat 84:168-195.

Winter Z, Gruschwitz P, Eger S, Touska F, Zimmermann K (2017) Cold temperature encoding by cutaneous TRPA1 and TRPM8-carrying fibers in the mouse. Front Mol Neurosci 10:209.

Woo SH, Ranade S, Weyer AD, Dubin AE, Baba Y, Qiu Z, Petrus M, Miyamoto T, Reddy K, Lumpkin EA, Stucky CL, Patapoutian A (2014)
Piezo2 is required for Merkel-cell mechanotransduction. Nature 509:622-626.

Woo SH, Lukacs V, de Nooij JC, Zaytseva D, Criddle CR, Francisco A, Jessell TM, Wilkinson KA, Patapoutian A (2015) Piezo2 is the principal mechanotransduction channel for proprioception. Nat Neurosci 18:1756-1762.

Zappia KJ, O’Hara CL, Moehring F, Kwan KY, Stucky CL (2017) Sensory neuron-specific deletion of TRPA1 results in mechanical cutaneous sensory deficits. eNeuro 4:ENEURO.0069-16.2017.

Zhang M, Wang Y, Geng J, Zhou S, Xiao B (2019) Mechanically activated piezo channels mediate touch and suppress acute mechanical pain response in mice. Cell Rep 26:1419-1431.e4.

Zurborg S, Piszczek A, Martínez C, Hublitz P, Al Banchaabouchi M, Moreira P, Perlas E, Heppenstall PA (2011) Generation and characterization of an Advillin-Cre driver mouse line. Molecular pain 7:66 